\title{
Organogel-Based Emulsified Systems, Food Applications, Microstructural and Rheological Features - A Review
}

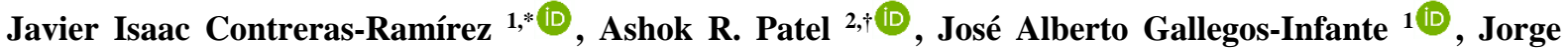 \\ Fernando Toro-Vázquez ${ }^{3}$ (D), Jaime David Pérez-Martínez ${ }^{3}$ (D), Walfred Rosas-Flores ${ }^{1(D)}$, Rubén \\ Francisco González-Laredo 1 (iD \\ 1 TecNM/Instituto Tecnológico de Durango, Departamento de Ingenierías Química y Bioquímica, Blvd. Felipe Pescador \\ 1830 Ote., Nueva Vizcaya, 34080 Durango, Dgo., México; contreras.ibq@gmail.com (J.I.C.-R.); \\ agallegos@itdurango.edu.mx (J.A.G.-I.); wrosas@itdurango.edu.mx (W.R.-F.); rubenfgl@itdurango.edu.mx (R.F.G.-L.); \\ 2 Guandong Technion Israel Institute of Technology, Biotechnology and Food Engineering, Daxue Road 241, Jinping \\ District, Shantou, Guangdong Province, China; ashok.patel@gtiit.edu.cn (A.R.P.); \\ 3 UASLP, Facultad de Ciencias Químicas, Av. Dr. Manuel Nava 6, Zona Universitaria, 78210 San Luis Potosí, S.L.P., \\ México; toro@uaslp.mx (J.F.T.-V.); jdavidperez@uaslp.mx (J.D.P.-M.); \\ $\dagger \quad$ Prof. Ashok R. Patel pass away on 13 May 2020. \\ * Correspondence: contreras.ibq@gmail.com;
}

Scopus Author ID 57221936500

Received: 28.04.2021; Revised: 26.05.2021; Accepted: 29.05.2021; Published: 9.06.2021

\begin{abstract}
Applications of organogelated emulsions in the food industry depend on their physicochemical features. The characteristics of organogelated emulsions bring together behaviors typical of an emulsion but also of an organogel. The development of these hybrids involves the use of stabilizing molecules such as surfactants and structuring agents. The physicochemical characteristics of organogelated emulsions depend on the interrelationship of different molecules that make them up. The differences in the nature of molecules, as well as methods of production and storage conditions, cause changes in the intermolecular interactions. The difference that exists between interactions of one set of components and another results in emulsified systems with unique characteristics. However, depending on the properties of each system, they will have different metastability. Structured emulsions have shown improved stability compared to some traditional emulsions. However, the mechanisms by which one system can maintain a metastable state longer than another have not been reported in much research. In recent years the food industry has shown interest in extending the metastability time of different emulsified systems. This article aims to review the latest advances in the characterization of organogelated emulsions and the relationship between microstructural and rheological properties and inter-component interactions in organogel W/O emulsions.
\end{abstract}

Keywords: food applications; interactions; metastability; microstructure; organogelated emulsions; van der Waals

(C) 2021 by the authors. This article is an open-access article distributed under the terms and conditions of the Creative Commons Attribution (CC BY) license (https://creativecommons.org/licenses/by/4.0/).

\section{Introduction}

The immediate needs of the world include the improvement of the nutritional properties of foods and the reduction of components that could be related to health problems. More and more countries are including legislative limits on the food industry to reduce the presence of trans fats and saturated fats in their products [1]. However, the task of reworking these food products to include an improvement in the nutritional profile in an appropriate way has not been an easy task. It is from these changes that it has become common to find organogels and 
emulsions as part of the formulation of food products and the development of some controlled release vehicles. While good results have been found in the partial substitution of solid fat to provide a desirable organogel-based texture and structure in some foods [2], there are still some limitations in mouthfeel and hydrophilic compatibility. Foods that have been successfully shown to improve health status and well-being and/or reduce disease risk have been termed functional foods. Functional foods are a growing market and a driving factor in the development of new products. The use of emulsified systems appears to be promising in the development of functional foods. In recent years, new mechanisms for developing emulsions have been developed, involving a gelation process that allows the formation of a complex microstructure [3]. Micro-structuring emulsions can be used in the food industry for fat reduction, probiotic release, and flavor release control $[4,5]$. Some research groups have suggested that structuring one of the phases in emulsions can lead to increased physical stability [6-8]. Structuring in emulsions can provide several advantages over organogels and emulsions, with fewer limitations. Different works $[9,10]$ mention how some factors, such as formulation (e.g., appropriate proportions of vegetable oil, gelling agent, and surfactant), are responsible for the microstructural and rheological features of organogelated emulsions, as they are responsible not only for structuring the continuous phase but can also alter the morphology of the droplets. However, even though it has been mentioned a lesser or greater interaction between components of structured emulsions, few reports are describing the types of interactions and how other variables modify them during their production. In addition, it has been mentioned that some changes in the intermolecular interactions have an impact on the physicochemical, thermodynamic and microstructural properties of these systems [11]. There are currently many articles focused on organogels and emulsions, from their characterization, different classifications, methods of obtaining them, and formulation variants and new applications in the pharmaceutical and food industries. In addition, there are not only a large number of original articles but also review articles that have been addressed by different groups of specialists in the field in the world. Metastability in organogelated emulsions is the main focus of interest [12-14]. Metastability can be defined as a state of apparent kinetic equilibrium where systems exhibit such small and slow changes that they are not perceived as unstable systems. However, although it is becoming common to find articles on systems known as "organogelated emulsions" or "emulsified organogels", they appear in fewer original data reports, and even fewer review publications can be found. Not to mention the scarce information on the behavior of intermolecular interactions in these organogel emulsions. Intermolecular interactions are defined as forces acting on different molecules or ions, causing them to attract or repel each other. These forces are relevant since they determine the physical properties in emulsified systems, they are responsible for the state of aggregation, melting and boiling point, surface tension, density, etc. The advantages presented by these hybrid systems (organogelated emulsions) as well as their reduced disadvantages have led to an increased interest in them by the industry. However, many of the molecular level aspects that provide these favorable metastable qualities to these systems are still unknown. Therefore, this review article aims to provide updated information on the main microstructural and rheological features of organogelated emulsions and how they relate to the intermolecular interactions present and point out their recent applications in the food industry. 


\section{Organogels, emulsions and organogelated emulsions}

\subsection{Organogels.}

Prior to the description of more complex systems, it is important to identify the systems from which we start (organogels and emulsions) and the generalities of each one. The presentation of organogels and emulsions individually will allow knowing the advantages and limitations of each system and the main characteristics that have allowed their wide use in the food industry. The use of organogels has become more interesting in the industrial sector since different scientific publications reported the association of saturated and trans fats with the appearance of cardiovascular diseases $[15,16]$, and health organizations such as the World Health Organization (WHO), Food and Drug Administration (FDA), and European Food Safety Authority (EFSA) recommended reducing their intake [17-20]. For many years, hydrogenation allowed the development of many products in the food industry based on vegetable oil. Hydrogenation basically consists of the saturation of carbon-carbon double bonds, converting cis geometric isomers into more stable trans isomers, and creating new positional isomers, where the double bonds are shifted to new positions along the fatty acid chain. This process allowed increasing the melting point of the fatty matrix obtaining partially crystallized systems at higher temperatures.

Organogels have an important application in the food industry as an alternative to the substitution of saturated and trans fats. Oleogelation is a technique that has been able to satisfy the need to effectively substitute the role of semisolid fats in texture and flavor properties in foods [21], as well as to maintain the nutritional profile of liquid vegetable oils [22, 23]. Organogels are obtained by dissolving the gelling agent in the organic solvent at high temperatures and then cooling the solution below the temperature of the solubility limit of the gelling agent, which allows the self-assembly of the gelling agent by various intermolecular forces such as hydrogen bridges and Van der Waals interactions [24], forming a threedimensional network that traps and immobilizes the liquid oil, resulting in a soft gel-like material with elastic characteristics (Figure 1A); its mechanical properties are dynamic where a pseudoplastic flow material is the most common to be found $[25,26]$. The applications of organogels in the food industry, as well as their characterization and components, have been well explained by different working groups [27-29].

Currently, much of the scientific research on organogels are focused on identifying the best gelator that is food grade or even accepted for pharmacological applications and provides the best physical characteristics and finding the best oil to structure [21, 30]. Organogels can be obtained from a wide range of organic gelators $[2,31]$. Some studies have shown that a combination of gelators can be more effective in structuring the oil [32, 33], however, a reduction in oil binding capacity due to interference from the same structurants has also been reported [34]. Organogels have been used not only to replace saturated and trans fats in foods [35], but also in the area of functional foods and nutraceuticals as controlled release systems for bioactive compounds of lipophilic nature [36]. It has been possible to increase the bioavailability of lipid-soluble molecules using organogels [24, 37]. The bioavailability of bioactive compounds depends on the micellization and solubilization of hydrophobic molecules [24]; in general terms, on the matrix of lipid components. However, one of the main challenges for organogels as carriers of compounds remains the sensitive response to the inclusion of water-soluble bioactive compounds, and their biocompatibility limitations with the physiological environment due to the high content of fatty matter, unlike hydrogels where they 
have a docile structure and greater biocompatibility. In addition, few organic liquids and gels are acceptable for drug and bioactive delivery by the different regulatory organizations [26]. This leads to the use of other systems with hydrophilic properties such as hydrogels or emulsions for many applications.

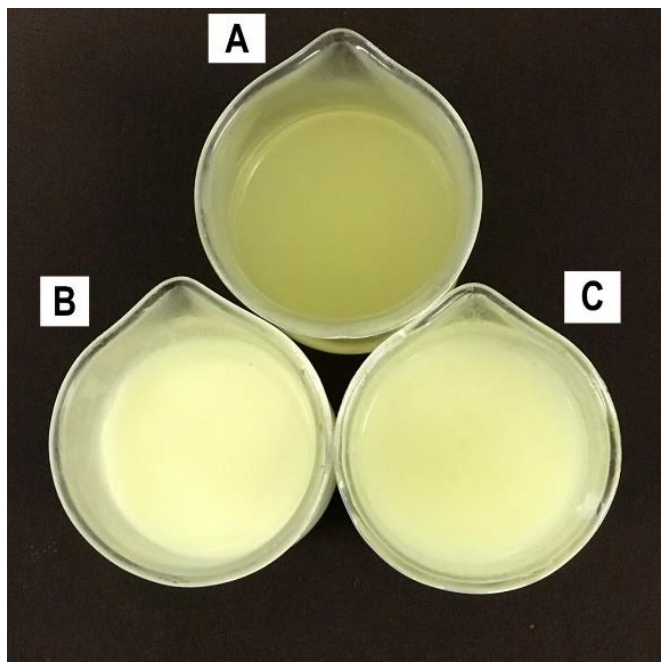

Figure 1. Appearance of semi-continuous systems: (A) Organogel; (B) Conventional emulsion; (C) W/O organogelated emulsion.

\subsection{Emulsions.}

Another alternative is the partial replacement of fat in foods is the incorporation of water using emulsions. In this way, it is possible to reduce the caloric content of some products, give amphiphilic characteristics and, in addition, provide a new consistency due to these soft materials. Emulsions can be defined as a mixture of two immiscible liquids dispersed as droplets in another that form the continuous phase, forming an interfacial layer between the two phases that can be occupied by surfactant molecules [38]. These surfactant molecules reduce the surface tension, which allows a better dispersion of the droplets. Emulsions can be of the oil-in-water $(\mathrm{O} / \mathrm{W})$ or water-in-oil (W/O) type, where the first-mentioned phase is the one in dispersed form (Figure 1B) [39]. In addition, there are other types of emulsions where the dispersed phase is itself another emulsion; such systems are known as multiple emulsions and can be oil-water-oil (O/W/O) or water-oil-water (W/O/W) [40, 41]. Emulsions containing two phases so opposite to each other are highly unstable. The instability of emulsions is due to the fact that the two phases that make up the emulsion (oil-water) have lower free energy than the emulsion itself, which is mainly due to the hydrophobic effect (i.e., the tendency to reduce the unfavorable contact area between oil and water) [42]. Therefore, during a sufficiently long storage time, emulsions tend to undergo physical changes leading to their eventual phase separation by mechanisms such as gravitational separation, flocculation, coalescence, and Ostwald ripening (Figure 2) [43].
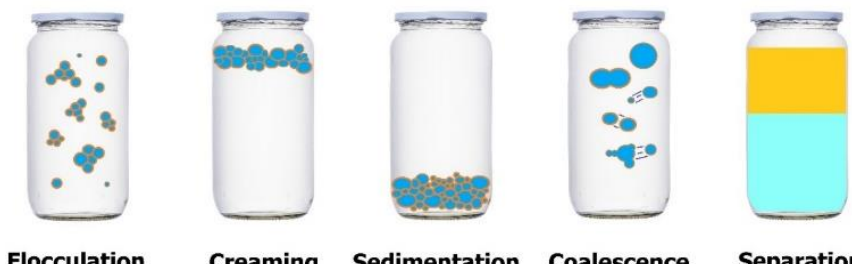

cculation

Creaming Sedimentation Coalescence

Separation

Figure 2. Instability phenomena in emulsified systems. 
Flocculation is the aggregation of droplets without coalescence [44], because the kinetic energy released by collisions drives the droplets to where the attractive forces operate, causing the droplets to stick together. The process is controlled by an equilibrium between van der Waals attractive forces and steric repulsive forces. Therefore, the forces holding the droplets together in this mechanism are weak and it is a reversible process [43]. Creaming is the formation of a cream layer at the top or a sediment layer at the bottom. This phenomenon is mainly due to the density difference between the phases [45]. It is a reversible process. Coalescence is the impact between droplets forming new larger droplets; this phenomenon is mainly due to the forces of attraction and repulsion between droplets. This instability is related to the stiffness and thickness of the surfactant layer and is an irreversible process [44]. Ostwald ripening (droplet coarsening): Due to molecular diffusion of the dispersed phase components through the continuous phase, it occurs from the small droplets to the large droplets until the small droplets disappear. The speed of this process is a function of the solubility of the dispersed phase in the continuous phase, increasing with temperature. It is due to the fact that the osmotic pressure inside the small droplets is higher than in the large droplets [43].

The DLVO (Derjaguin, Landau, Verwey \& Overbeek) theory can be used to describe the interactions between droplets qualitatively, assuming that the stability of emulsions is due to long-range interactions occurring between droplets [46]. This theory considers van der Waals forces (VA) and electrostatic forces (VR). These forces are a function of the distance (d) between the droplets. Depending on the relative strengths of the attractive and repulsive potentials (Figure 3), VA can dominate VR when d is very large or very small (between the two minima). Whereas, at intermediate separations, the repulsions that occur exceed the attractive terms or potentials and create an energy barrier [47]. Generally, the first minimum is so deep that once the droplets exceed it, the aggregation between them becomes irreversible. In an emulsion, if the average distance between the droplets is greater than the distance corresponding to the second minimum, the system increases in energy by adding the droplets and therefore, the droplets flocculate. Now suppose the layer formed by the surfactants around the droplets becomes unstable. In that case, coalescence occurs, and this is the final stage in the life of a droplet within an emulsion $[46,47]$.

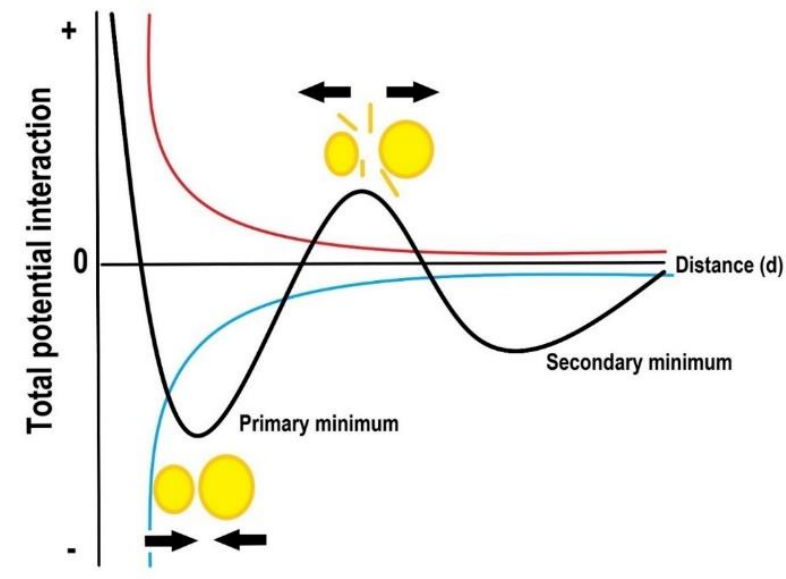

Figure 3. Diagram of potential interactions between molecules as a function of distance.

Although it has been achieved with the latest technological advances to delay phase separation in emulsions with modifications in droplet sizes (nanoemulsions 20-500 $\mathrm{nm}$ and microemulsions <100 nm) (Figure 4A) [41, 48], considerably reducing the surface tension [49] and even using solid particles (Pickering emulsions) that function as a physical barrier that prevents contact between the liquid of the droplets (Figure 4B) [50]; emulsions still retain some 
typical characteristics such as particle displacement in their continuous phase (high molecular mobility) and a lower degree of molecular organization than organogels (Figure 4B) [50]; emulsions still retain some typical characteristics of dispersions such as particle displacement in their continuous phase (high molecular mobility) and a lower degree of molecular organization than organogels; this added to the reduction of momentary interfacial energies, over time causes emulsions mostly to be thermodynamically unstable [13]. The lack of stability is still a key challenge for their use as controlled delivery vehicles for nutrients and flavorings $[51,52]$. In the food industry, the most important challenges are that traditional emulsions have limited use in mimicking the sensory and textural properties that solid fat can provide. This impacts the final products where aspects such as color, viscosity, hardness, elasticity, flavor, mouthfeel (e.g., melting, creaminess, lubricity, among others) become more relevant [53-55].

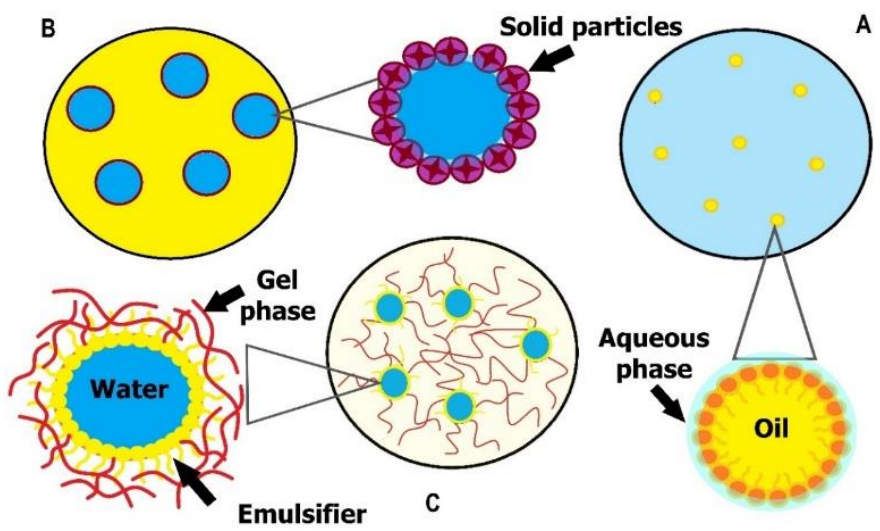

Figure 4. Types of emulsions: (A) Nanoemulsions; (B) Pickering emulsions; (C) Organogelated emulsions.

\subsection{Organogelated emulsions.}

It has become more common in the literature articles related to emulsified gels or gel emulsions [11]. Gel emulsions can be divided depending on the state of the droplets into gels filled with emulsified droplets and gels aggregated by emulsified droplets. In the former, the continuous phase forms a gel-like matrix that functions as a support for the dispersed phase. In the second type, the droplets flocculate in an ordered manner maintaining a network structure. However, as already reported by Lin et al., [56], most of these systems present a combination of both structures. The inclusion of a gelation method in one of the phases of an emulsion has made it possible to increase the shelf life of the emulsion by up to four months without phase separation [29]. One of the advantages of keeping one of the phases gelled or structured has been to obtain a higher mechanical resistance and a better binding capacity between the phases (oil-water) by means of structures with elastic behavior [11, 57]. Organogelated emulsions have a stable gel-like network at room temperature. These qualities are made possible by including components that enhance attractive intermolecular interactions [34, 58]. Interventional studies involving animals or humans and other studies that require ethical approval must list the authority that provided approval and the corresponding ethical approval code.

Currently, most of the structuring processes reported on emulsions focus on the oil phase. Although it is possible to gel the oily phase when it is in the dispersed or continuous form [11], this will depend on the type of intended application, ranging from topical application, inclusion in food for flavor maintenance, compound encapsulation, antioxidant protection and controlled drug release [59-65]. W/O organogelated emulsions have a 
continuous oil phase structured from a self-assembling gelling agent that imparts semi-solid organogel-like characteristics [66, 67], these gelling molecules form a three-dimensional network that traps oil and dispersed water droplets (Figure 4C) [67, 68]. This reduces the continuous phase mobility and free energy. Oleogelation in emulsions is an alternative approach to oleogels and conventional emulsions, as they fulfill the objective of obtaining semi-solid characteristics and preserving the amphiphilic properties of an emulsion [69]. These new properties in emulsions allow the food industry to develop low-fat products while maintaining a higher content of unsaturated fat [70], but also new mechanisms of controlled release of both hydrophilic and lipophilic bioactive compounds can be employed since the gellike matrix protects these compounds in their different stages of digestion. In addition, a higher bioaccessibility efficiency of bioactive related to faster lipid digestion in organogelated emulsions than in organogels has been reported [71]. There are several results related to the efficiency of organogelated emulsions to increase the bioaccessibility of bioactive molecules with lipophilic characteristics [72]. Some compounds, such as lupeol, betulin and quercetin, have shown good results with increased permeability and bioaccessibility [72-74].

\subsection{Obtaining and characterization of organogelated emulsions.}

The methods of obtaining W/O organogelated emulsions are not very different from the methods used in organogels and emulsions [75], which consist of dispersion of the dispersed phase and structuring agents. There are several methods of preparing gel emulsions, depending on their purpose (e.g., nutrient protection or improving mechanical properties), the different methods for some gel emulsions have already been addressed in other review articles [76]. The preparation of emulsions involves an increase in interfacial area. In some cases, chemical energy can be used in the form of concentration or osmotic pressure gradients to form small droplets in the interfacial region. Physical methods are the most commonly used methods and are divided into high- and low-energy methods, where low-energy approaches rely on the spontaneous formation of small droplets in mixed oil-water emulsion systems and when the solution or environmental conditions change, e.g., temperature or composition [77]. In these methods, the free energy comes from physicochemical processes rather than mechanical force. Some low-energy methods are isothermal. There is a wide range of temperatures, and they do not require rapid cooling, saving energy and cost, and being the most suitable methods for encapsulating heat-sensitive compounds. Some of these methods included spontaneous emulsification, by physicochemical processes, for example, in the so-called "ouzo effect" [78] by titration of the organic phase; only oil, water and a water-miscible solvent are used without using surfactants. In some cases, mechanical dispersion can be difficult when the fluids to be emulsified have too different viscosities. An alternative methodology is the production of an emulsion by phase inversion. The isothermal phase inversion method is opposite to spontaneous emulsification with respect to the phases [79]. The direct inversion method is based on catastrophic inversion while applying high shear [80]. In thermal methods, a temperature change is required, e.g., the phase inversion temperature method. This method does not require specialized equipment, so it is still considered a low cost. The method is typically used to form nanoemulsions from a mixture of a relatively hydrophilic nonionic surfactant, oil and water, this mixture is heated above the phase inversion temperature (PIT) and then rapidly cooled [77]. These methods depend on changes in the structural and physicochemical characteristics of the surfactants during heating. Using PIT, the surfactant is evenly distributed between the organic phase and the aqueous phase. At higher temperatures, 
the surfactants are mostly hydrophobic due to dehydration of their polar heads and, conversely, at lower temperatures, these polar heads are mostly hydrophilic and highly hydrated [77]. The driving force of the phase inversion process is related to a massive migration of surfactant from oil to water and changes in viscosity.

High-energy mechanisms are dispersion and force methods (Figure 5). These allow the breakup of droplets, obtain very small particle sizes, increase the interaction area [81]; and are the most widely used. The free energy comes from the mechanical force applied to the system (such as shear, turbulence, or cavitation), although most of this energy is lost as heat due to friction. The most commonly used methods for producing emulsions are high-pressure homogenization and microfluidization, which can be used both on an industrial and laboratory scale. Homogenization allows extremely small particle sizes (down to $1 \mathrm{~nm}$ ) to be obtained. However, there is a higher risk of blockage at the outlet of the homogenization chamber, which can be quite difficult to resolve [82]. The microfluidizer uses a high-pressure (500 to 20,000 psi) positive displacement pump, which forces the product through the interaction chamber, producing very fine submicron-range particles. Ultrasonication and in situ emulsification are also suitable but are mainly used on a laboratory scale and not for commercial production [82].
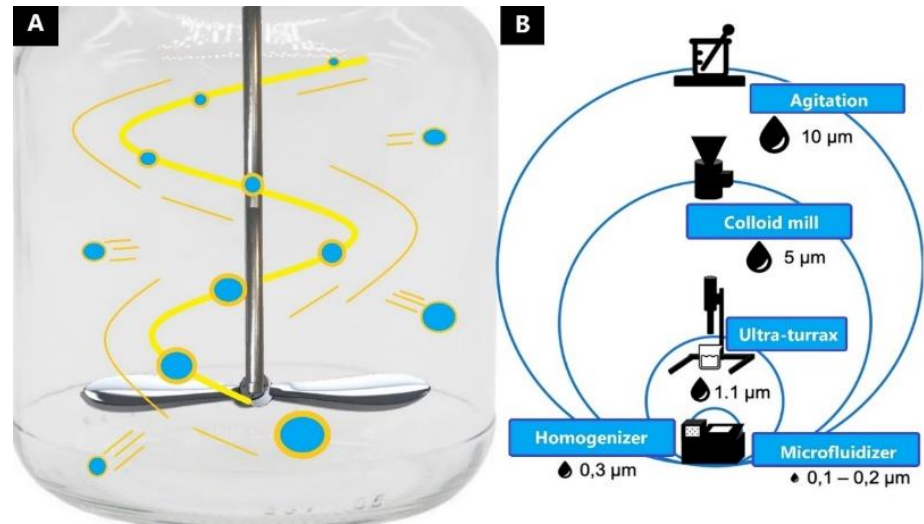

Figure 5. High energy methods for obtaining emulsions: (A) Schematic mechanical dispersion process; (B) Dispersion equipment and droplet sizes obtained.

Raviadaran et al. [83] used an ultrasonic process to prepare W/O emulsions, finding no sedimentation for 14 days at $4{ }^{\circ} \mathrm{C}$. Also, Clausse et al. [84] obtained W/O emulsions with a mean particle diameter of micrometer level using a high-pressure homogenizer and polyglycerol polyricinoleate (PGPR) as surfactant. However, speaking only of organogelated emulsions W/O, self-assembly based on low molecular weight compounds and biopolymers are among the most relevant, reducing allergenic and cytotoxicity effects [85]. However, new compounds such as chain globulin from Hyptis suaveolens seed, which has been shown to have thermostable emulsifying and gelling properties, continue to be proposed [86]. The methods of obtaining W/O organogelated emulsions involve heating of all the oil phase components (liquid oil, surfactant and gelling agent), and agitation/mixing mechanism for homogenization of the components and including during the process the dispersion of the aqueous phase. During the process, biomolecules of different nature may or may not be included in any of its phases (oil and/or water) [67]. Methods that include the use of high pressures have also been reported, although this has been in O/W (oil in water) gel emulsions, where the dependence of the rheological properties on the pressure used during the process of obtaining emulsions with gellike characteristics has been observed. An increase in the elastic behavior $\left(G^{\prime}\right)$ at higher pressures $(80 \mathrm{MPa})$ and less dependence on frequency has been reported, as well as higher 
retention of the continuous liquid phase [87]. This is important because, in the substitution of fat in foods, it is important to resemble lard in terms of rheological properties and texture, so it is expected that future research will address the relationship of high pressures on the characteristics of W/O type organogelated emulsions since they have a higher proportion of oily phase.

W/O organogelated emulsions are homogeneous-looking systems, which means that they maintain a state of kinetic equilibrium, at least momentary, unlike nanoemulsions that look homogeneous because the droplets have a highly uniform distribution in the continuous phase (prolonged kinetic stability). Organogelated emulsions are systems with an appearance more similar to organogels (Figure 6). The opacity in emulsified systems is largely determined by the light scattering, which in turn depends on the suspended particles they contain, however, whereas, in conventional emulsions, this would depend only on the dispersed droplets (size and quantity mainly) [88], in organogelated emulsions the crystalline structures that form the threedimensional network in the continuous oil phase are added (Figure 6B). As mentioned above, W/O organogelated emulsions follow a similar pattern in terms of microstructural and rheological characteristics. A good characterization allows identifying mainly the destabilization mechanisms by evaluating their physicochemical properties at the initial stage and during storage of organogelated emulsions [43].
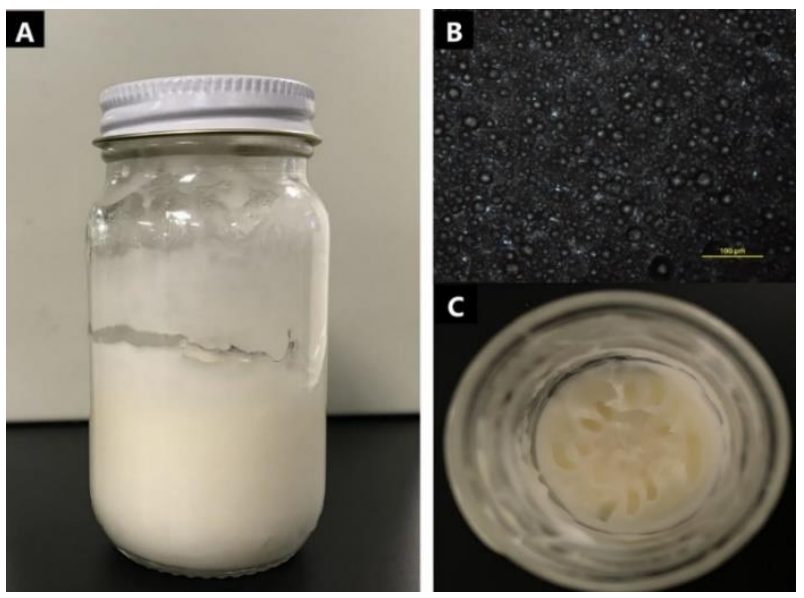

Figure 6. W/O organogel emulsion: (A) Homogeneous appearance; (B) Presence of dispersed droplets and crystalline structures in continuous phase; (C) Creamy consistency (semi-solid).

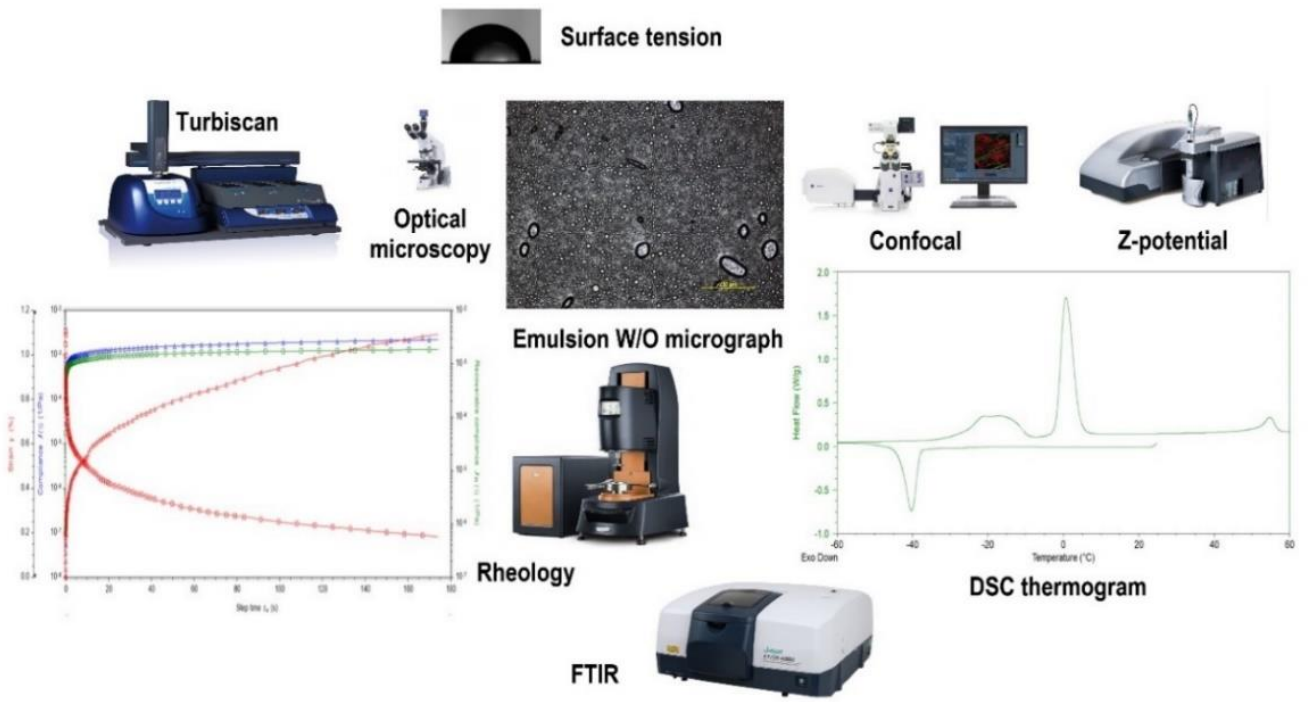

Figure 7. Technologies used in the characterization of emulsified systems. 
The physicochemical characterization of emulsions is fundamental since each formulation and process variant produces small changes that modify the stability and general behavior of the emulsion. Therefore, a physicochemical characterization should be performed from the microstructural to the macro level, including a general evaluation of the different intermolecular interactions [89]. All these tests and technologies complement each other (Figure 7), so it is necessary to have the equipment indicated for each specific test and know their rationale and how they carry out certain processes.

The microstructure of organogel emulsions includes morphology, droplet sizes statically and dynamically, as well as the identification of some destabilization phenomena. The microstructure can be evaluated by optical microscopy [72], laser and confocal scanning microscopy [90, 91], fluorescence microscopy [92], transmission electron microscopy (TEM) [93], scanning electron microscopy (SEM) [91], small and wide-angle X-ray scattering (SAXS and WAXS) [69, 91, 94] and atomic force microscopy (AFM) [95]. The microstructure of organogel W/O emulsions is affected by the type of oil, the type of surfactant and gelling agent, but also on the amount in which these are present; as this affects not only the size of the suspended particles but also influences the syneresis and swelling properties of the network. The particle size in a sample as complex as an emulsion has an important effect on the stability of the emulsion. A smaller particle size can retard instability phenomena such as flocculation and coalescence in emulsions [96]. Therefore, an important parameter to consider in organogel emulsions is the polydispersity index (PDI) that can be obtained from dynamic light scattering. The PDI indicates the degree of variation or amplitude of a Gaussian bell that represents the particle sizes suspended in these systems. Zeta potential can be used to indicate the stability of a colloid, where higher values indicate greater stability and smaller molecules or particles [97]. However, although it is an important complementary test to PDI, in organogelated emulsions, it presents some accuracy difficulties in W/O systems where the oil phase is structured.

Intramolecular properties, such as enthalpies, crystallization and glass transition shaving, have been successfully evaluated by differential scanning calorimetry (DSC) [98]. Particle-particle interactions can be investigated by isothermal titration calorimetry (ITC) [99] and nuclear magnetic resonance (NMR) [100]. Fourier transform infrared spectroscopy (FTIR) allows the evaluation of the different chemical and molecular bonds corresponding to each of the elements in organogel emulsions [101]. The band ranges in which the different bonds can be identified (e.g., $\mathrm{OH},-\mathrm{CH},-\mathrm{CH}_{3}$ ) are already almost entirely found in the literature. It is possible to identify under which conditions a higher bond strength is obtained [97]. This may be a key factor in identifying the emulsifying ability of some molecules.

Surface hydrophobicity is closely related to the solubility properties, rheology and emulsifying ability of different compounds, although this is most commonly seen with the use of proteins [97], it is also reproducible for the evaluation of other compounds using fluorescence spectroscopy. Evaluations of hydrophobic and hydrophilic properties in emulsions have been performed from wetting and contact angle measurements using goniometers [102]. It is possible to measure the change in surface tension at the macro level at the interface as it decreases when active particles adsorb at the oil-water interface [91]. This can be done with the use of goniometers [102], tensiometers [103] and interfacial rheology tests [104], also by the Wilhelmy plate method and the du Noüy ring method, which measure the force required to pass an object through an interface [105], among others. In emulsion formation, dispersing one of the phases increases the interfacial area and, consequently, the interfacial energy [106]. The Gibbs free energy in any system will always tend to reduce 
spontaneously [107]. Therefore, smaller interface energy will allow for longer stability in emulsified systems. Interfacial tension is the interfacial energy per unit length. Because of this, surface tension is closely related to emulsifying capacity and droplet size. It has been reported that a higher interfacial viscosity is related to an interaction effect between surfactant molecules and structuring molecules with amphiphilic characteristics, resulting in a tight arrangement of active molecules at the interface [103, 108]. Measurement of interface tension and the measurement of the interfaces' viscoelastic properties can provide information on the interactions between emulsifiers and co-emulsifiers used in these organogelated emulsions. Interfacial swelling rheology is affected by the structure of the molecules and their interactions. Rheological properties such as elastic and viscous moduli, complex viscosity, among others, help to predict the stability during storage of organogelated emulsions [67]. The rheological properties of organogelated emulsions are influenced by the solid fraction (structures and crystallized compounds) and the interaction potential of these systems. Some investigations from rheological tests have related the interaction between surfactants in emulsions to the degree of frequency dependence $[109,110]$. It is also possible to relate aspects such as particle size and viscosity changes, indicating the aggregation of droplets due to intermolecular interaction changes. Even after a complete characterization, it is important to understand that the final properties of an organogelated emulsion will largely depend on its composition. In addition, many of its properties may still show changes due to external factors, such as temperature, time and storage conditions [111]. Some systems have shown a significant increase in particle size with higher heat treatment. These changes are related to the molecular aggregation of the organogelated emulsions. In addition, higher incubation and/or storage temperatures can alter the hydrophobicity of the surface (interface), favoring flocculation phenomena [112]. Because of this, it is advisable to monitor these properties during different time intervals to identify other variables that may have an impact on the stability of organogelated emulsions. Although the physicochemical aspect is one of the most important to evaluate organogelated emulsions, it is important to consider lipid oxidation. Since considering a long shelf life in these systems and containing a large amount of oil in their continuous phase, W/O organogelated emulsions may be exposed to lipid oxidation. It is possible that structuring the oil phase of these systems may reduce the oxidation process, however, it is important to include the characterization and evaluation of these organogelated emulsions in a chemical quality assessment. This process can be controlled by forming lipid hydroperoxide and the thiobarbituric acid reactive substance (TBARS) content [113]. It is important to perform complementary studies to those mentioned above, these should include solubility [114], permeability $[74,115]$ and simulated digestions $[81,116]$.

\section{Components of organogelated emulsions}

\subsection{Continuous phase.}

Most dietary fats are composed of mixtures of several triacylglycerides; these mixtures may simultaneously contain both a solid and a liquid fraction. The solid fraction may be dispersed as particles in the liquid phase, or it may interact to form three-dimensional networks similar to a flocculated colloidal gel while trapping the liquid oil [117]. The interactions that form the fat crystal networks are primarily due to weak van der Waals forces and, when subjected to mechanical stresses, the systems exhibit pseudoplastic behavior [118]. This behavior is desirable for many food products such as butter or shortening, so the organogelated 
emulsions that come to exhibit the most similar behavior are those of the W/O type. However, differences in the composition of vegetable oils affect the mechanical stability of emulsified systems. Emulsions can be affected by chemical degradation (i.e., oxidation, reduction, or hydrolysis reactions). Emulsions containing polyunsaturated lipids can have oxidation reactions, while some biopolymers used as emulsifiers can be depolymerized by hydrolysis, this can affect the characteristics of the food matrix of which they are part, causing discoloration of pigments and loss of flavors [119]. This can become a problem since both the use of biopolymers and polyunsaturated lipids are widely used in the development of organogelated emulsions. There are even many results that the use of mostly unsaturated lipids in organogelated emulsions and organogels favors the formation of more elastic and temperature resistant structures [67, 120]. More stable systems can be obtained with long-chain unsaturated fatty acids than with medium-chain saturated fatty acids because, with the former, there is a greater interaction of the attractive type, which forms stronger structures $[72,121]$. The stability in organogelated emulsions is due to the fact that the molecules present steric hindrance and/or electrostatic repulsion between the droplets [122] so that they retain a pseudoplastic behavior and, in some cases, a high electronegativity [123]. It should be emphasized that the chemical reaction rate can also be retarded by a smaller droplet size leading to a higher surface area at the oil-water interface. Chemical reactions may also occur slower in organogelated emulsions compared to nanoemulsions since a smaller fraction of light waves can penetrate an optically opaque system [124], so the apparent disadvantages of using oils consisting mostly of unsaturated fatty acids such as canola or olive oil appear to be attenuated in these W/O organogelated emulsions.

\subsection{Emulsifiers and structuring agents.}

The main function of an emulsifier is to protect the dispersed droplets from various destabilization phenomena. The difference between emulsifiers and structurants is that the former is incorporated at the interface thanks to their amphiphilic characteristics (Figure 8). Structuring agents, on the other hand, tend to maintain the physicochemical characteristics of organogelated emulsions by generating changes in the viscosity and microstructure of the continuous phase, reducing changes in the interactions between droplets [125]. Emulsifiers and gelling agents are an essential part of the development of W/O organogelated emulsions. There is a wide range of organogelators and emulsifiers classified into low molecular weight and polymeric compounds [126, 127]. Different molecules can act as both structuring and emulsifying agents. Low molecular weight molecules are mainly amphiphilic molecules whose stabilization process mainly reduces the interfacial tension between oil and water. Biopolymers generally have hydrophobic activity and are not surfactants (polysaccharides), except for some types (proteins), so their main function is to increase the system's viscosity. Insoluble particles allow the development of Pickering systems with the use of silica particles, latex, among others. The choice of surfactant is often a function of its Hydrophilic Lipophilic Balance (HLB) value (Table 1), in simple terms, surfactants being molecules with amphiphilic characteristics, will always tend to be more soluble and affine for one of the phases (oil or water) [128]. However, the stability of W/O organogelated emulsions will depend on the chemical affinity between the continuous oil phase and the hydrophobic residues of the emulsifiers and co-emulsifiers and the size of the molecule, temperature dependence and the critical micellar concentration. Needless to say, when working with W/O organogelated emulsions, a mostly lipophilic surfactant $(<6)$ should be included. Among the most commonly used surfactants are 
polyglycerol polyricinoleate (PGPR), sorbitan monooleate (Span80), and some mixtures of monoglycerides, with which structured W/O emulsions have been developed. There are amphiphilic molecules such as phospholipids and glycolipids that are good emulsifiers and are able to protect probiotics of interest in emulsified systems, however, these molecules are easily oxidized. Some research has used soy lecithin in organogelated emulsions. The reported results showed improved viability of probiotics (L. acidophilus and B. lactis) for up to 42 days without exhibiting lipid oxidation [129]. This was because the prooxidant compounds were trapped in the micellar fibers of soy lecithin [69]. It was also reported that higher amounts of organogelating agents are more effective in retarding lipid oxidation. The fibrillar structures that soy lecithin or monoglycerides can form are responsible for retarding lipid oxidation and reducing molecular collision [130], which in W/O organogelated emulsions retards instability and phase separation phenomena. It has also been reported how the mixture of monoglycerides with other surfactant components increases organogel systems' stability that includes an aqueous phase, delaying phase separation [32].

Table 1. HLB Scale.

\begin{tabular}{c|c} 
Function & HLB Range \\
\hline Defoamers & $1-3$ \\
\hline W/O system stabilizers & $4-6$ \\
\hline Wetting agents & $7-9$ \\
\hline O/W system stabilizers & $8-18$ \\
\hline Detergents & $13-15$ \\
\hline Solubilizers & $10-18$
\end{tabular}

The synergistic effect between gelling agents, emulsifiers and other co-emulsifying additives has already been reported in different investigations (Table 2). When several compounds are used as stabilizers of organogelated emulsions, each one is sought to have a specific predominant activity, from forming structures in the continuous phase (gelling agent) to decreasing surface tension and improving dispersion (surfactant). However, some can perform more than one function according to their nature, which will depend on the chemical affinity between components.

Table 2. Set of compounds used for the stabilization of organogels and W/O emulsions.

\begin{tabular}{|c|c|c|}
\hline Compound & Stabilized system & References \\
\hline Lecithin and phytosterols & \multirow{3}{*}{ Organogels } & {$[131]$} \\
\hline Monoglycerides and lecithin & & {$[32]$} \\
\hline Ethyl cellulose and lecithin & & {$[132]$} \\
\hline $\begin{array}{l}\text { Protein isolate, polysaccharides (high } \\
\text { methoxy pectin, kappa carrageenan } \\
\text { and sodium alginate), and PGPR }\end{array}$ & $\mathrm{W} / \mathrm{O}$ emulsions & {$[133]$} \\
\hline $\begin{array}{l}\text { PGPR, sodium caseinate and } \\
\text { glucuronic acid. }\end{array}$ & \multirow{3}{*}{$\begin{array}{l}\text { W/O emulsions } \\
\text { (gelled water) }\end{array}$} & {$[134]$} \\
\hline $\begin{array}{l}\text { PGPR, lecithin, gums (guar and } \\
\text { xanthan gum) and } \\
\text { carboxymethylcellulose. }\end{array}$ & & {$[84]$} \\
\hline PGPR and pectin & & {$[135]$} \\
\hline Span80 and chitosan & \multirow{6}{*}{ W/O organogelated emulsions } & {$[136]$} \\
\hline Whey protein isolate and PGPR & & {$[137]$} \\
\hline PGPR and stearin crystals & & {$[61]$} \\
\hline Lecithin and stearic acid & & [69] \\
\hline Citrus pectin and Tp-palmitate & & {$[138]$} \\
\hline Monoglycerides and PGPR & & {$[67]$} \\
\hline
\end{tabular}


There have been several reports of systems stabilized with PGPR in recent years where the drop diameter is smaller and remains with less variation than with lecithin $[84,139]$. This is due to the fact that PGPR has the ability to impart an elastic behavior to the oil-water interface. In addition, surfactants such as PGPR can actively anchor to the crystal lattice found in the continuous oil phase thanks to their hydrocarbon tails (Figure 8) [140], which reinforces the structure in organogelated emulsions and retards coalescence phenomena [67]. Other additives that improve the stability of W/O systems with PGPR are sodium salts. This is because there is a lower attractive force between the droplets and a lower interfacial tension, which allows resistance to coalescence [141]. The molecular weight of the structurant has also been found to be an important factor for the mean droplet diameter [136]. It is possible to maintain the properties of W/O organogelated emulsions with less variation over time by including the appropriate stabilizing molecules for each system. The stabilizing molecules in an organogelated emulsion have specific functions, although collectively, they are used to reduce variations in intermolecular interactions.

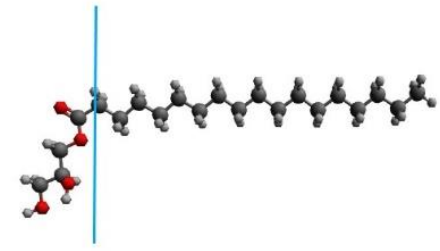

Monoglyceride

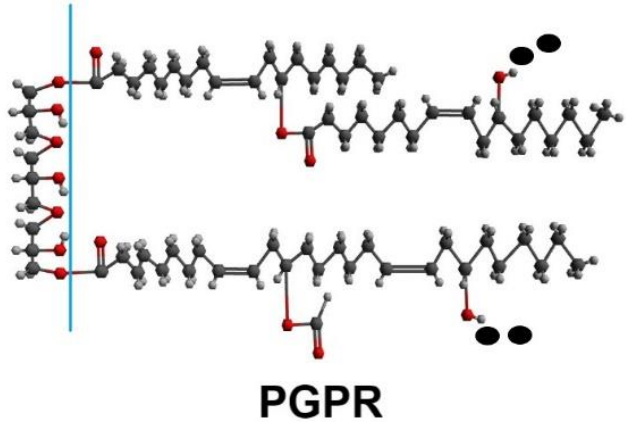

Figure 8. Molecular structure of emulsifiers. The blue line divides the hydrophilic part from the hydrophobic residues. The black dots denote polyricinoleic acid chains in PGPR.

\section{Intermolecular interactions}

In a molecule, atoms are joined together by intramolecular forces (ionic, metallic, or covalent bonds). However, intermolecular interactions are the forces that act on different molecules, causing them to attract or repel each other. Intermolecular interactions determine in organogelated emulsions, as well as in other systems, the physicochemical properties (molecular aggregation, melting and boiling points, solubility, surface tension, density, among others). The interactions are weak forces, but together they determine the results of organogelated emulsions. It is possible to learn more about intermolecular interactions in textbooks, however, in this review, we have mentioned how different characteristics and improvements in stability have been related to these interactions in organogelated emulsions. Stabilizing or emulsifying molecules reduce the interfacial tension and orient their structure to minimize the Gibbs free energy, providing a favorable thermodynamic arrangement for the emulsion [142]. Therefore, the relevance of the different interactions will also depend on the nature of our compounds.

\subsection{Van der Waals.}

Van der Waals interactions occur when there is a moderate distance between molecules. These interactions depend on the specific surface area and mass of the suspended particle and the nature of the medium in which it is found [143]. Van der Waals interactions mainly encompass attractive forces between molecules. The van der Waals interactions can be divided into dipole-dipole, induced dipole-dipole and induced dipole-induced dipole-instantaneous 
dipole forces. Dipole-dipole forces occur when molecules have an asymmetric distribution of their electrons and these are in the most electronegative proximity. In this way, polar molecules can be found that have one part with a negative partial charge and another with a positive partial charge. The interaction occurs when two molecules approach each other and there is an attraction between the positive end of one molecule and the negative end of the other. This interaction will be more relevant in a system the greater the electronegative difference between the bonded atoms. Although these have a separate mention of their relevance in emulsified systems, this section includes hydrogen bonds. Induced dipole-dipole interactions occur between a polar molecule and an apolar molecule. In this case, the charge of a polar molecule distorts the electronic cloud of an apolar molecule when they are sufficiently close, transiently converting it into a dipole. Induced dipole-instantaneous dipole interactions are also known as London forces. These interactions occur between non-polar molecules and are caused by irregularities in the electronic cloud where an instantaneous dipole can momentarily form and induce another by proximity. Attractive van der Waals interactions between two water droplets in a continuous oil phase are of smaller magnitude when the refractive indices and/or dielectric constants are similar [141]. In some cases, fatty crystals can be found at the oil-water interface of structured emulsions. Through van der Waals interactions, such crystals will form a crystal lattice that prevents droplet diffusion from the lattice and contact with neighboring droplets [144]. Enhanced molecular aggregation sustained by van der Waals interactions has been found from ordered flocculation of droplets, increasing the stiffness and mechanical strength of the whole structured emulsion using PGPR and diglycerides [145, 146].

\subsection{Electrostatic repulsion.}

When two particles approach each other, they are exposed to two forces with different natures and opposite orientations [143]. Unlike Van der Waals interactions, electrostatic repulsive forces depend on the surface charge of the suspended particles. The interplay between attraction and repulsion interactions is well described in the DLVO theory, named after the four scientists who developed it: Derjaguin, Landau, Verwey and Overbeek [143]. Electrostatic interactions occur between ions of equal charge. In simple terms, ions with charges of the same sign will repel each other. Coulumb's law defines this force. Electrostatic repulsion can be evaluated in emulsions by considering the variability of the Zeta potential with respect to an added ionic strength (e.g., the inclusion of salts) [147]. Since interaction by the components of the emulsified system with these molecules can represent a reduction of the static charge, causing this attraction to overcome the electrostatic repulsion between the particles [148, 149]. This is why these interactions are often also called salt bridging and can be found with greater relevance in organogelated emulsions that include the use of proteins. In addition, $\mathrm{NaCl}$ dissolves by an attraction between its ions with the opposite charge of the water molecule in the presence of water, forming a hydration layer around certain proteins, which is sometimes reflected in the oil-water interface of some systems. It has been possible to stabilize emulsions using carboxymethyl starch and xanthan gum [150]. This is because xanthan gum and anionic starch contain negatively charged carboxymethyl groups. They increase the electrostatic repulsion between the droplets in combination with an emulsion, limiting attractive type interactions [151]. These aforementioned interactions are more frequent than ion-dipoleinduced interactions, i.e., between an ion and a polar molecule, however, they cannot be ruled out in such complex systems. 


\subsection{Hydrophobic interaction.}

In W/O organogelated emulsions, the mostly lipophilic emulsifiers have a higher frequency of hydrophobic residues, not to mention the gelling agent in the continuous phase, which must have a higher degree of hydrophobicity. Non-ionic (i.e., uncharged) surfactants with low HLB are generally used in W/O emulsions. Therefore, in the first instance, steric stabilization can be expected to be the dominant mechanism [140]. Steric stabilization is an effect caused by the influence of a functional group of a molecule on the course of a chemical reaction, on the conformation, or the intermolecular interactions of a molecule. In other words, it occurs when the volume occupied by a functional group or atom in a molecule prevents another part of the same molecule from interacting. The chemical structure of the molecules mainly governs the efficiency of this stabilization. However, even if this type of stabilization is found in emulsions, charges and dipoles may still be present at the interface, resulting in significant long-range electrostatic repulsion between droplets across the low dielectric constant oil phase [94]. In an aqueous medium, hydrophobic molecules associate with each other for thermodynamic reasons. That is, when lipid molecules are in a medium where there is a considerable amount of water, they tend to become ordered, aligning their hydrocarbon chains and the entropy in the system increases. Thus, a mixture of surfactant and gelling agent of lipophilic nature can be expected to rely mostly on hydrophobic interactions and hydrogen bonding. Zhang et al., [152] have shown that the interaction between $\beta$-lactoglobulin ( $\beta$-lg) and phospholipids is mainly hydrophobic. Similar reports have been made using $\beta-1 g$ and PGPR [153]. In systems with an elastic interface, a time-dependent increase in this elasticity can be found due to sulfide bridge interactions using proteins [154]. However, this increase in elasticity can also occur in W/O organogelated emulsions with the use of PGPR. An increase in the hydrophobicity of cellulose microgels has allowed the development of W/O emulsions with up to $20 \%$ of the aqueous phase, presenting stability during one month, this could be proved by FTIR, SEM and WAXS [94]. There are some studies where denaturing reagents are used to evaluate the interaction forces in Pickering-type emulsions. Sodium dodecyl sulfate has been used to evaluate hydrophobic interactions, while urea has been used for hydrogen bonds and dithiothreitol for disulfide bonds. It was found that hydrophobic interactions were vital for the interaction of emulsion droplets [155]. Since these interactions can participate in the connection of some particles by deamidation, which can improve the surface hydrophobicity of gliadin, making the deamidated gliadin particles have a higher surface hydrophobicity [156], which, in summary, allows obtaining more stable Pickering systems for up to 32 days [157]. However, Wang et al., [157] also highlight the relevance of hydrogen bridges in the stability of these Pickering systems.

\subsection{Hydrogen bonding interactions.}

Hydrogen bridging bonds, as mentioned above, are a special case of dipole-dipole interaction. This occurs when a hydrogen atom is covalently bonded to a very electronegative element of a very small size. These occur mainly with $\mathrm{F}, \mathrm{O}$ and $\mathrm{N}$ atoms. While it may not be the strongest bond in the first instance, the abundance with which it occurs in W/O organogelated emulsions makes it one of the main interactions. Hydrogen bonds are the strongest intermolecular interactions in W/O organogelated emulsions and are responsible for maintaining the emulsifier at the interface as the polar head forms hydrogen bonds with the water molecules. In W/O organogelated emulsions, it is common to find monoglycerides and 
surfactants such as PGPR. As mentioned above, these have proven to be efficient stabilizers of these systems. Good stability of organogelated emulsions has been reported for up to 30 days using these compounds [67]. These emulsions show almost no presence of instability phenomena, attributed to the elasticity provided by these stabilizers. Other investigations have attributed this behavior to the hydrogen bonds formed due to the hydrophilic heads of some lipophilic compounds [158]. Within the characterization, it is possible to identify the presence of stronger hydrogen bonds by the width of the bands in FTIR tests, which corresponds in most cases to the increased interaction of the polar heads of amphiphilic molecules and some coemulsifiers with the water molecules found in the dispersed phase. It has also been possible to improve the chemical stability of some compounds, such as beta-carotene, in high internal phase emulsions (HIPE) based on the control of hydrogen bonds [159]. Hydrogen bonds were formed between starch modified with octenyl succinic anhydride and tannic acid [159]. These results are important, since as mentioned above, emulsions have shown good results for the encapsulation of bioactive compounds such as some polyphenols. It is also well known that the polysaccharides used in these emulsions can form complexes with polyphenols through hydrogen bonds, hydrophobic, electrostatic and van der Waals interactions [160], the first two bonds being the most relevant. Some research groups have developed gel emulsions where from FTIR, ${ }^{1} \mathrm{H}-\mathrm{NMR}$ spectroscopy and computational studies found that hydrogen bonds between sulfonamide and amide groups are the main factors in forming and preserving the gellike network structures [161]. Higher mechanical strength was also found by increasing the hydrogen bonding site. Currently, studies of the interfacial distribution of phenolic antioxidants are mostly studied in Pickering emulsions through nanoparticle interactions [162]. Moreover, most of these studies involve the use of proteins as stabilizers [163]. However, few articles report the stabilization mechanisms from the molecular point of view (interactions involved) in organogelated emulsions. Therefore, there is still a margin to expand the knowledge on this subject since all the interactions mentioned above are responsible for the greater or lesser stability of an organogelated emulsion.

\section{Stability or metastability}

As mentioned throughout this review article, the aforementioned instability phenomena occur due to an imbalance of different attractive and repulsive interactions (i.e., hydrogen bridges, Van der Waals forces, electrostatic repulsions) that modify the stability of W/O organogelated emulsions and emulsified systems in general $[164,165]$. When attractive forces exceed repulsive forces or vice versa, the emulsion system is unstable. It will exhibit coalescence and phase separation. However, there is another case where the forces may be similar in range and magnitude, albeit with dominance variations between them at some points in space-time. This will result in significant minimal changes (i.e., apparent equilibrium) that will accumulate to eventual long-term phase separation, becoming a metastable system. Metastability refers to the fact that, although organogelated emulsions may reach some equilibrium over a long period of time (even more than a year), this period is relative. Their phases will eventually separate $[13,42,166,167]$. Therefore, it is important to prolong this period of metastability to obtain systems with a longer duration of use without changes in their desired characteristics. 


\section{Conclusions}

The traditional concept of emulsion lacks description and adaptation to the types of emulsions existing today. Likewise, the constant demand in the food industry for new products and the improvement of existing ones, from the functional to the nutritional aspect, has led to the development of emulsified systems with unique physicochemical characteristics. They also maintain their amphiphilic properties and maintain a state of metastability for much longer. W/O organogelated emulsions have proven to be metastable systems with great potential for application in the area of functional foods. New generations of researchers in the area of functional food and biomolecule vehicle development should consider not only the traditional fundamentals of emulsion development but also other complementary systems such as organogels. It is possible to make a combination of both technologies. It is also important to find answers as to why one system is more metastable than another. This is possible by expanding the knowledge of how different intermolecular interactions act on the microstructural, morphological, thermodynamic and rheological properties of W/O organogelated emulsions. At present, no work has been reported where the effect of the variables of time, temperature and concentration of stabilizers (gelling agents and surfactants) on intermolecular interactions is explored in depth. This knowledge will define and predict the metastability of organogelated emulsions and expand their possible applications in the food industry.

\section{Funding}

This research was funded by the Strengthening and Development of Scientific and Technological Infrastructure program (Grants Nos. 253333 and 224651) and the Basic Science program (Grant No. 241241) from CONACyT (National Council of Science \& Technology).

\section{Acknowledgments}

Author J.I. Contreras-Ramírez is grateful for the graduate scholarship (Grant No. 607796) from CONACyT, Mexico.

\section{Conflicts of Interest}

The authors declare no conflict of interest. The funders had no role in the design of the study, in the collection, analyses, or interpretation of data, in the writing of the manuscript, or in the decision to publish the results.

\section{References}

1. Stender, S.; Astrup, A.; Dyerberg, J. Tracing artificial trans fat in popular foods in Europe: a market basket investigation. BMJ Open 2014, 4, 5218, https://doi.org/10.1136/bmjopen-2014-005218.

2. García-Andrade, M; Gallegos-Infante, J.A.; González-Laredo, R.F. Organogels as lipid profile improvers in meat and dairy matrices. Ciencia UAT 2019, 14, 121-132, https://doi.org/10.29059/cienciauat.v14i1.1129.

3. Balakrishnan, G.; Nguyen, B.T.; Schmitt, C.; Nicolai, T.; Chassenieux, C. Heat-set emulsion gels of casein micelles in mixtures with whey protein isolate. Food Hydrocoll. 2017, 73, 213-221, https://doi.org/10.1016/j.foodhyd.2017.07.005.

4. Leal-Calderon, F.; Thivilliers, F.; Schmitt, V. Structured emulsions. Curr. Opin. Colloid Interface Sci. 2007, 12, 206-212, https://doi.org/10.1016/j.cocis.2007.07.003.

5. Muschiolik, G. Multiple emulsions for food use. Curr. Opin. Colloid Interface Sci. 2007, 12, 213-220, https://doi.org/10.1016/j.cocis.2007.07.006. 
6. Benichou, A.; Aserin, A.; Garti, N. Double emulsions stabilized with hybrids of natural polymers for entrapment and slow release of active matters. Adv. Colloid Interface Sci. 2004, 108, 29-41, https://doi.org/10.1016/j.cis.2003.10.013.

7. Surh, J.; Vladisavljević, G.T.; Mun, S.; McClements, D.J. Preparation and Characterization of Water/Oil and Water/Oil/Water Emulsions Containing Biopolymer-Gelled Water Droplets. J. Agric. Food Chem. 2007, 55, 175-184, https://doi.org/10.1021/jf061637q.

8. Dickinson, E. Double Emulsions Stabilized by Food Biopolymers. Food Biophys. 2011, 6, 1-11, https://doi.org/10.1007/s11483-010-9188-6.

9. Patel, A.R.; Rodriguez, Y.; Lesaffer, A.; Dewettinck, K. High internal phase emulsion gels (HIPE-gels) prepared using food-grade components. RSC Adv. 2014, 4, 18136-18140, https://doi.org/10.1039/c4ra02119c.

10. Patel, A.R.; Dumlu, P.; Vermeir, L.; Lewille, B.; Lesaffer, A.; Dewettinck, K. Rheological characterization of gel-in-oil-in-gel type structured emulsions. Food Hydrocoll. 2015, 46, 84-92, http://dx.doi.org/10.1016/j.foodhyd.2014.12.029.

11. Lin, D.; Kelly, A.L.; Maidannyk, V.; Miao, S. Effect of structuring emulsion gels by whey or soy protein isolate on the structure, mechanical properties, and in-vitro digestion of alginate-based emulsion gel beads. Food Hydrocoll. 2021, 110, 106165-106177, https://doi.org/10.1016/j.foodhyd.2020.106165.

12. Tran, T.; Green, N.L.; Ghosh, S.; Rosseau, D. Encapsulation of water-in-oil emulsion droplets within crystal spheroids. Colloids Surf. A Physicochem. Eng. Asp. 2017, 524, 1-7, https://doi.org/10.1016/j.colsurfa.2016.12.054.

13. McClements, D.J.; Jafari, S.M. Improving emulsion formation, stability and performance using mixed emulsifiers: A review. Adv. Colloid Interf. Sci. 2018, 251, 55-79, https://doi.org/10.1016/j.cis.2017.12.001.

14. Toro-Vázquez, J.F.; Pérez-Martínez, J.D. Thermodynamic Aspects of Molecular Gels. In Molecular Gels: Structure and Dynamics. R.G. Weiss (Ed.). London, England: The Royal Society of Chemistry. 2018, 57-87.

15. Liu, A.G.; Ford, N.A.; Hu, F.B.; Zelman, K.M.; Mozaffarian, D.; Kris-Etherton, P.M. A healthy approach to dietary fats: understanding the science and taking action to reduce consumer confusion. Nutr. J. 2017, 16, 53, https://doi.org/10.1186/s12937-017-0271-4.

16. The European Food Safety Authority (EFSA), Scientific and technical assistance on trans fatty acids. EFSA Supporting Publications 2018, https://doi.org/10.2903/sp.efsa.2018.EN-1433.

17. World Health Organization (WHO), Healthy diet. Available online: https://cutt.ly/Sv8Raxq (accessed on 25 April 2021).

18. Food and Drug Administration. Final Determination Regarding Partially Hydrogenated Oils (Removing Trans Fat). Available online: https://cutt.ly/ov8RSgS (accessed on 25 April 2021).

19. World Health Organization (WHO), REPLACE Trans Fat - An action package to eliminate industriallyproduced trans fat from the global food supply. Available online: https://cutt.ly/tv8R28S (accessed on 27 July 2020).

20. European Commission. Commission Regulation (EU) 2019/649. Available online: https://cutt.ly/Wv8TrCF (accessed on 25 April 2021).

21. Singh, A.; Auzanneau, F-I.; Rogers, M.A. Advances in edible oleogel technologies - A decade in review, Food Res. Int. 2017, 97, 307-317, https://doi.org/10.1016/j.foodres.2017.04.022.

22. Zhu, Y.; Bo, Y.; Liu, Y. Dietary total fat, fatty acids intake, and risk of cardiovascular disease: a dose response meta-analysis of cohort studies. Lipids Health Dis. 2019, 18, 91, https://doi.org/10.1186/s12944-019-10352.

23. Palla, C.A.; Wasinger, M.F.; Carrín, M.E. Monoglycerides oleogels as fat replacers in filling creams for sandwich cookies. J. Sci. Food Agric. 2020, 101, 2398-2405, https://doi.org/10.1002/jsfa.10863.

24. Davidovich-Pinhas, M. Oleogels: a promising tool for delivery of hydrophobic bioactive molecules. Fut. Sci. 2016, 7, 1-3, https://doi.org/10.4155/tde.15.83.

25. Tang, S.; Liu, X.Y.; Strom, C.S. Producing Supramolecular Functional Materials Based on Fiber Network Reconstruction. Adv. Funct. Mater. 2009, 19, 2252-2259, https://doi.org/10.1002/adfm.200801590.

26. Yogev, S.; Mizrahi, B. Organogels as a Delivery System for Volatile Oils. ACS Appl. Polym. Mater. 2020, 2 , 2070-2076, https://dx.doi.org/10.1021/acsapm.0c00269.

27. Kouzounis, D.; Lazaridou, A.; Katsanidis, E. Partial replacement of animal fat by oleogels structured with monoglycerides and phytosterols in frankfurter sausages. Meat Sci. 2017, 130, 38-46, https://doi.org/10.1016/j.meatsci.2017.04.004. 
28. Pehilivanoğlu, H.; Demirci, M.; Toker, O.S.; Konar, N.; Karasu, S.; Sagdic, O. Oleogels, a promising structured oil for decreasing saturated fatty acid concentrations: Production and food-based applications. Crit. Rev. Food Sci. 2018, 58, 1330-1341, https://doi.org/10.1080/10408398.2016.1256866.

29. Pușcaș, A.; Mureșan, V.; Socaciu, C.; Muste, S. Oleogels in Food: A Review of Current and Potential Applications. Foods 2020, 9, 70, https://doi.org/10.3390/foods9010070.

30. García-Andrade, M.; González-Laredo, R.F.; Rocha-Guzmán, N.E.; Rosas-Flores, W.; Moreno-Jiménez, M.R.; Peña-Ramos, E.A.; Gallegos-Infante, J.A. Influence of ethyl cellulose in a multicomponent mixture (sorbitan monopalmitate-vegetable oils) on physicochemical properties of organogels. Rev. Mex. Ing. Quim. 2020, 19, 953-968, https://doi.org/10.24275/rmiq/Alim801.

31. Avedaño-Vásquez, G.; De la Peña-Gil, A.; Charó-Alvarado, M.E.; Charó-Alonso, M.A.; Toro-Vázquez, J.F. Self-Assembly of Symmetrical and Asymmetrical Alkyl Esters in the Neat State and in Oleogels. Front. Sustain. Food Syst. 2020, 4, 1-21, https://doi.org/10.3389/fsufs.2020.00132.

32. Aguilar-Zárate, M.; De la Peña-Gil, A.; Álvarez-Mitre, F.M.; Charó-Alonso, M.A.; Toro-Vázquez, J.F. Vegetable and Mineral Oil Organogels Based on Monoglyceride and Lecithin Mixtures. Food Biophys. 2019, 14, 326-345, https://doi.org/10.1007/s11483-019-09583-1.

33. Rodríguez-Hernández, A.K.; Pérez-Martínez, J.D.; Gallegos-Infante, J.A.; Toro-Vázquez, J.F.; Ornelas-Paz, J.J. Rheological properties of ethyl cellulose-monoglyceride-candelilla wax oleogel vis-a-vis edible shortenings. Carbohydr. Polym. 2021, 252, 117171, https://doi.org/10.1016/j.carbpol.2020.117171.

34. Barroso, N.G.; Okuro, P.K.; Ribeiro, A.P.B.; Cunha, R.L. Tailoring Properties of Mixed-Component Oleogels: Wax and Monoglyceride Interactions Towards Flaxseed Oil Structuring. Gels 2020, 6, 5, https://doi.org/10.3390/gels6010005.

35. Alejandre, M.; Astiasarán, I.; Ansorena, D.; Barbut, S. Using canola oil hydrogels and organogels to reduce saturated animal fat in meat batters. Food Rest. Int. 2019, 122, 129-136, https://doi.org/10.1016/j.foodres.2019.03.056.

36. Sosa-Gutiérrez, D.; Toro-Vázquez, J.F.; Cano-Sarmiento, C.; Grube-Pagola, P.; Aparicio-Saguilan, A.; Torres-Palacios, C.; Acosta-Osorio, A.; García, H. Betulinic Acid Nanogels: Rheological, Microstructural Characterization and Evaluation of their Anti-inflammatory Activity. Curr. Drug Deliv. 2020, 17, 1-12, https://doi.org/10.2174/1567201817999200817154003.

37. Storz, T.A.; Zetzl, A.K.; Barbut, S.; Cattaruzza, A.; Marangoni, A.G. Edible oleogels in food products to help maximize health benefits and improve nutritional profiles. Lipid. Technol. 2012, 24, 151-154, https://doi.org/10.1002/lite.201200205.

38. Kasprzak, M.M.; Macnaughtan, W.; Harding, S.; Wilde, P.; Wolf, B. Stabilisation of oil-in-water emulsions with non-chemical modified gelatinised starch. Food Hydrocoll. 2018, 81, 409-418, https://doi.org/10.1016/j.foodhyd.2018.03.002.

39. Goodarzi, F.; Zendehboudi, S. A Comprehensive Review on Emulsions and Emulsion Stability in Chemical and Energy Industries. Can. J. Chem. Eng. 2019, 97, 281-309, https://doi.org/10.1002/cjce.23336.

40. Ali, A.; Iqbal, S.; Ilyas, A.; Khan, H.; Asad, M.H.H.B.; Fatima, N.; Akhtar, N. Anti-pollution cosmetic-based one-step formation of w/o/w multiple emulsion containing D-biotin for skin protection: fabrication and in vitro and in vivo evaluation. Drug Deliv. Transl. Res. 2019, 9, 1117-1132, https://doi.org/10.1007/s13346019-00655-w.

41. Niknam, S.M.; Escudero, I.; Benito, J.M. Formulation and Preparation of Water-In-Oil-In-Water Emulsions Loaded with a Phenolic-Rich Inner Aqueous Phase by Application of High Energy Emulsification Methods. Foods 2020, 9, 1411-1430, https://doi.org/10.3390/foods9101411.

42. Wooster, T.J.; Labbett, D.; Sanguansri, P.; Andrews, H. Impact of microemulsion inspired approaches on the formation and destabilization mechanisms of triglyceride nanoemulsions. Soft Matter 2016, 12, 1425-1435, https://doi.org/10.1039/c5sm02303c.

43. Chung, C.; McClements, D.J. Characterization of Physicochemical Properties of Nanoemulsions: Appearance, Stability, and Rheology. In Nanoemulsions, Academic Press. 2018, 547-576, https://doi.org/10.1016/B978-0-12-811838-2.00017-5.

44. McClements, J.; McClements, D.J. Standardization of Nanoparticle Characterization: Methods for Testing Properties, Stability and Functionality of Edible Nanoparticles. Crit. Rev. Food Sci. Nutr. 2016, 56, 37-41, https://doi.org/10.1080/10408398.2014.970267.

45. McClements, D.J. Edible nanoemulsions: Fabrication, properties, and functional performance. Soft Matter 2011, 7, 2297-2316, https://doi.org/10.1039/c0sm00549e. 
46. López-Mendoza, A.; Chávez-Guajardo, A.E. Determination of the Conditions for Agglomeration of Molybdenite Fines in the Presence of Kerosene Emulsion Through the Extended DVLO Theory. EJERS 2021, 6, 80-86, http://dx.doi.org/10.24018/ejers.2021.6.1.2328.

47. Xu, C-y.; Zhou, T-t.; Wang, C-1.; Liu, H-y.; Zhang, C-t.; Hu, F-n.; Zhao, S-w.; Geng, Z-c. Aggregation of polydisperse soil colloidal particles: Dependence of Hamaker constant on particle size. Geoderma 2020, 359, 113999, https://doi.org/10.1016/j.geoderma.2019.113999.

48. McClements, J.D.; Jafari, S.M. General aspects of nanoemulsions and their formulation. In Nanoemulsions, Academic Press. 2018, 3-20, https://doi.org/10.1016/B978-0-12-811838-2.00001-1.

49. Zhang, X.; Qi, B.; Xie, F.; Hu, M.; Sun, Y.; Han, L.; Li, L.; Zhang, S.; Li, Y. Emulsion stability and dilatational rheological properties of soy/whey protein isolate complexes at the oil-water interface: Influence of pH. Food Hydrocoll. 2021, 113, 106391, https://doi.org/10.1016/j.foodhyd.2020.106391.

50. Li, F.; Li, X.; Huang, K.; Luo, Y.; Mei, X. Preparation and characterization of pickering emulsion stabilized by hordein-chitosan complex particles. J. Food Eng. 2021, 292, 110275-110283, https://doi.org/10.1016/j.jfoodeng.2020.110275.

51. Driscoll, D.F. Pharmaceutical and Clinical Aspects of Lipid Injectable Emulsions. J. Parenter. Enter. Nutr. 2017, 41, 125-134, https://doi.org/10.1177/0148607116673187.

52. Raman, M.; Almutairdi, A.; Mulesa, L.; Alberda, C.; Beattie, C.; Gramlich, L. Parenteral Nutrition and Lipids. Nutrients 2017, 9, 388-399, https://doi.org/10.3390/nu9040388.

53. Chen, Y.; She, Y.; Zhang, R.; Wang, J.; Zhang, X.; Gou, X. Use of starch-based fat replacers in foods as a strategy to reduce dietary intake of fat and risk of metabolic diseases. Food Sci. Nutr. 2020, 8, 16-22, https://doi.org/10.1002/fsn3.1303.

54. Marangoni, A.G.; van Duynhoven, J.P.M.; Acevedo, N.C.; Nicholson, R.A.; Patel, A.R. Advances in our understanding of the structure and functionality of edible fats and fat mimetics. Soft Matter 2020, 16, 289306, https://doi.org/10.1039/C9SM01704F.

55. Patel, A.R.; Nicholson, R.A.; Marangoni, A.G. Applications of fat mimetics for the replacement of saturated and hydrogenated fat in food products. Curr. Opin. Food Sci. 2020, 33, 61-68, https://doi.org/10.1016/j.cofs.2019.12.008.

56. Lin, D.; Kelly, A.L.; Miao, S. The role of mixing sequence in structuring O/W emulsions and emulsion gels produced by electrostatic protein-polysaccharide interactions between soy protein isolate-coated droplets and alginate molecules. Food Hydrocoll. $\quad$ 2021, $\quad$ 113, https://doi.org/10.1016/j.foodhyd.2020.106537.

57. Meng, Z.; Qi, K.; Guo, Y.; Wang, Y.; Liu, Y. Macro-micro structure characterization and molecular properties of emulsion-templated polysaccharide oleogels. Food Hydrocoll. 2018, 77, 17-29, https://doi.org/10.1016/j.foodhyd.2017.09.006.

58. Moran-Valero, M.I.; Ruiz-Henestrosa, V.M.P.; Pilosof, A.M.R. Synergistic performance of lecithin and glycerol monostearate in oil/water emulsions. Colloid. Surface. B 2017, 151, 68-75, https://doi.org/10.1016/j.colsurfb.2016.12.015.

59. Hodge, S.M.; Rousseau, D. Flocculation and coalescence in water-in-oil emulsions stabilized by paraffin wax crystals. Food Res. Int. 2003, 36, 695-702, https://doi.org/10.1016/S0963-9969(03)00036-X.

60. Sawalha, H.; den Adel, R.; Venema, P.; Bot, A.; Flöter, E.; van der Linden, E. Organogel-emulsions with mixtures of $\beta$-sitosterol and $\gamma$-oryzanol: Influence of water activity and type of oil phase on gelling capability. J. Agric. Food Chem. 2012, 60, 3462-3470, https://doi.org/10.1021/jf300313f.

61. Prichapan, N.; McClements, D.J.; Klinkesorn, U. Iron Encapsulation in Water-in-Oil Emulsions: Effect of Ferrous Sulfate Concentration and Fat Crystal Formation on Oxidative Stability. J. Food Sci. 2018, 83, 309317, https://doi.org/10.1111/1750-3841.14034.

62. Barbut, S.; Marangoni, A.G.; Thode, U.; Tiensa, B.E. Using Canola Oil Organogels as Fat Replacement in Liver Pâté. J. Food Sci. 2019, 84, 2646-2651, https://doi.org/10.1111/1750-3841.14753.

63. Sawalha, H.; Venema, P.; Bot, A.; Flöter, E.; Lan, Y.; van der Linden, E. Effects of Oil Type on Sterol-Based Organogels and Emulsions. Food Biophys. 2020, 2020, 1-10, https://doi.org/10.1007/s11483-020-09654-8.

64. Botega, D.C.Z.; Nogueira, C.; de Moura, N.M.; Martinez, R.M.; Rodrigues, C.; Barrera-Arellano, D. Influence of Aqueous Matrices into Candelilla Wax Organogels Emulsions for Topical Applications. J. Am. Oil Chem.' Soc. 2021, 98, 317-328, https://doi.org/10.1002/aocs.12438.

65. de Souza Paglarini, C.; Vidal, V.A.; Ribeiro, W.; Badan Ribeiro, A.P.; Bernardinelli, O.D.; Herrero, A.M.; Ruiz-Capillas, C.; Sabadini, E.; Rodrigues-Pollonio, M.A. Using inulin-based emulsion gels as fat substitute in salt reduced Bologna sausage. J. Sci. Food Agric. 2021, 101, 505-517, https://doi.org/10.1002/jsfa.10659. 
66. Toro-Vázquez, J.F.; Mauricio-Pérez, R.; González-Chávez, M.M.; Sánchez-Becerril, M.; Ornelas-Paz, J.J.; Pérez-Martínez, J.D. Physical properties of organogels and water in oil emulsions structured by mixtures of candelilla wax and monoglycerides. Food Res. Int. 2013, 54, 1360-1368, https://doi.org/10.1016/j.foodres.2013.09.046.

67. Contreras-Ramírez, J.I.; Gallegos-Infante, J.A.; Pérez-Martínez, J.D.; Dibildox-Alvarado, E.; RochaGuzmán, N.E.; Moreno Jiménez, M.R.; González-Laredo, R.F.; Rosas-Flores, W. Influence of vegetable oil, monoglycerides and polyglycerol polyricinoleate into the physical stability of organogel-emulsion (w/o) systems. SN Applied Sciences 2020, 2, 1343-1355, https://doi.org/10.1007/s42452-020-3144-y.

68. Jiang, Y.; Liu, L.; Wang, B.; Yang, X.; Chen, Z.; Zhong, Y.; Zhang, L.; Mao, Z.; Xu, H.; Sui, X. Polysaccharide-based edible emulsion gel stabilized by regenerated cellulose. Food Hydrocoll. 2019, 91, 232-237, https://doi.org/10.1016/j.foodhyd.2019.01.028.

69. Gaudino, N.; Ghazani, S.M.; Clark, S.; Marangoni, A.G.; Acevedo, N.C. Development of lecithin and stearic acid based oleogels and oleogel emulsions for edible semisolid applications. Food Res. Int. 2019, 116, 7989, https://doi.org/10.1016/j.foodres.2018.12.021.

70. Dreher, J.; Blach, C.; Terjung, N.; Gibis, M.; Weiss, J. Formation and characterization of plant-based emulsified and crosslinked fat crystal networks to mimic animal fat tissue. J. Food Sci. 2020, 85, 421-431, https://doi.org/10.1111/1750-3841.14993.

71. Yu, H.; Huang, Q. Improving the oral bioavailability of curcumin using novel organogel-based nanoemulsions. J. Agric. Food Chem. 2012, 60, 5373-5379, https://doi.org/10.1021/jf300609p.

72. Ojeda-Serna, I.E.; Rocha-Guzmán, N.E.; Gallegos-Infante, J.A.; Cháirez-Ramírez, M.H.; Rosas-Flores, W.; Pérez-Martínez, J.D.; Moreno-Jiménez, M.R.; González-Laredo, R.F. Water-in-oil organogel based emulsions as a tool for increasing bioaccessibility and cell permeability of poorly water-soluble nutraceuticals. Food Res. Int. 2019, 120, 415-424, https://doi.org/10.1016/j.foodres.2019.03.011.

73. Cháirez-Ramírez, M.H.; Moreno-Jiménez, M.R.; González-Laredo, R.F.; Gallegos-Infante, J.A.; RochaGuzmán, N.E. Lupane-type triterpenes and their anti-cancer activities against most common malignant tumors: A review. EXCLI J 2016, 15, 758-771, https://doi.org/10.17179/excli2016-642.

74. Rocha-Guzmán, N.E.; Cháirez-Ramírez, M.H.; Contreras-Ramírez, J.I.; Pérez-Martínez, J.D.; Rosas-Flores, W.; Ornelas-Paz, J.J.; Moreno-Jiménez, M.R.; González-Laredo, R.F.; Gallegos-Infante, J.A. Physical characterization and permeability of lupeol by use of organogel-based emulsions (o/w). Lett. App. NanoBioSci. 2020, 9, 861-865, https://doi.org/10.33263/LIANBS91.861865.

75. Gravelle, A.J.; Marangoni, A.G.; Davidovich-Pinhas, M. Ethylcellulose oleogels. In Edible oleogels, (2nd ed.). Marangoni A.G.; Garti N. (Eds.). Urbana, IL: AOCS Press 2018, 331-362.

76. Lin, D.; Kelly, A.L.; Miao, S. Preparation, structure-property relationships and applications of different emulsion gels: Bulk emulsion gels, emulsion gel particles, and fluid emulsion gels. Trends Food Sci. Technol. 2020, 102, 123-137, https://doi.org/10.1016/j.tifs.2020.05.024.

77. Anton, N.; Vandamme, T.F. The universality of low-energy nano-emulsification. Int. J. Pharm. 2009, 377, 142-147, https://doi.org/10.1016/j.ijpharm.2009.05.014.

78. Ganachaud, F.; Katz, J.L. Nanoparticles and Nanocapsules Created Using the Ouzo Effect: Spontaneous Emulsification as an Alternative to Ultrasonic and High-Shear Devices. Chem. Phys. Chem. 2005, 6, 209216, https://doi.org/10.1002/cphc.200400527.

79. Zhang, Z.; Vriesekoop, F.; Yuan, Q.; Liang, H. Effects of nisin on the antimicrobial activity of d-limonene and its nanoemulsion. Food Chemistry 2014, 150, 307-312, https://doi.org/10.1016/j.foodchem.2013.10.160.

80. Züge, L.C.B.; Haminiuk, C.W.I.; Maciel, G.M.; Silveira, J.L.M.; Scheer, A.P. Catastrophic inversion and rheological behavior in soy lecithin and Tween 80 based food emulsions. J. Food Eng. 2013, 116, 72-77, https://doi.org/10.1016/j.jfoodeng.2012.12.008.

81. Liu, W.; Gao, H.; McClements, D.J.; Zhou, L.; Wu, J.; Zou, L. Stability, rheology, and $\beta$-carotene bioaccessibility of high internal phase emulsion gels. Food Hydrocoll. 2019, 88, 210-217, https://doi.org/10.1016/j.foodhyd.2018.10.012.

82. Shams, N.; Sahari, M.A. Nanoemulsions: Preparation, structure, functional properties and their antimicrobial effects. Appl. Food Biotechnol. 2016, 3, 138-149, https://doi.org/10.22037/afb.v3i3.11773.

83. Raviadaran, R.; Ng, M.H.; Manickam, S.; Chandran, D. Ultrasound-assisted water-in-palm oil nanoemulsion: Influence of polyglycerol polyricinoleate and $\mathrm{NaCl}$ on its stability. Ultrason. Sonochem. 2019, 52, 353-363, https://doi.org/10.1016/j.ultsonch.2018.12.012. 
84. Clausse, D.; Lanoisellé, J.L.; Pezron, I.; Saleh, K. Formulation of a water-in-oil emulsion encapsulating polysaccharides to improve the efficiency of spraying of plant protection products. Colloid. Surf. APhysicochem. Eng. Asp. 2019, 536, 96-103, https://doi.org/10.1016/j.colsurfa.2017.07.032.

85. Costa, A.L.R.; Gomes, A.; de Figueiredo Furtado, G.; Tibolla, H.; Menegalli, F.C.; Cunha, R.L. Modulating in vitro digestibility of Pickering emulsions stabilized by food-grade polysaccharides particles. Carbohydr. Polym. 2020, 227, 115344, https://doi.org/10.1016/j.carbpol.2019.115344.

86. De la Cruz-Torres, L.F.; Mancilla-Margalli, N.A.; VillaVelázquez-Mendoza, C.I.; Carrazco-Peña, L.D.; Chan-Cupul, W.; Osuna-Castro, J.A.; Toro-Vázquez, J.F.; Pérez-Martínez, J.D. Thermal and emulsifying properties of globulins from chain (Hyptis suaveolens L. Poit) seeds. J. Food Process. Preserv. 2020, 44, 14652, https://doi.org/10.1111/jfpp.14652.

87. Bi, C-h.; Wang, P-l.; Sun, D-y.; Yan, Z-m.; Liu, Y.; Huang, Z-g.; Gao, F. Effect of high-pressure homogenization on gelling and rheological properties of soybean protein isolate emulsion gel. J. Food Eng. 2020, 277, 109923, https://doi.org/10.1016/j.jfoodeng.2020.109923.

88. Zhang, J.; Reineccius, G.A. Factors controlling the turbidity of submicron emulsions stabilized by food biopolymers and natural surfactant. LWT Food Sci. Technol. 2016, 71, 162-168, https://doi.org/10.1016/j.lwt.2016.03.035.

89. Zhang, L.; Li, Z.; Wang, L.; Sun, D. High temperature stable W / O emulsions prepared with in-situ hydrophobically modified rodlike sepiolite. J. Colloid Interf. Sci. 2017, 493, 378-384, https://doi.org/10.1016/j.jcis.2017.01.056.

90. Dai, L.; Zhan, X.; Wei, Y.; Sun, C.; Mao, L.; McClements, D.J.; Gao, Y. Composite zein - propylene glycol alginate particles prepared using solvent evaporation: Characterization and application as Pickering emulsion stabilizers. Food Hydrocoll. 2018, 85, 281-290, https://doi.org/10.1016/j.foodhyd.2018.07.013.

91. Safieh, P.; Pensini, E.; Marangoni, A.; Lamont, K.; Ghazani, S.M.; Callaghan-Patrachar, N.; Strüder-Kypke, M.; Peyronel, F.; Chen, J.; Rodriguez, B.M. Natural emulsion gels and lecithin-based sorbents: A potential treatment method for organic spills on surface waters. Colloid. Surface. A 2019, 574, 245-259, https://doi.org/10.1016/j.colsurfa.2019.04.090.

92. Mun, S.; Kim, J.; McClements, D.J.; Kim, Y.R.; Choi, Y. Fluorescence imaging of spatial location of lipids and proteins during digestion of protein-stabilized oil-in-water emulsions: A simulated gastrointestinal tract study. Food Chem. 2017, 219, 297-303, https://doi.org/10.1016/j.foodchem.2016.09.158.

93. Uzun, S.; Kim, H.; Leal, C.; Padua, G.W. Ethanol-induced whey protein gels as carriers for lutein droplets. Food Hydrocoll. 2016, 61, 426-432, https://doi.org/10.1016/j.foodhyd.2016.05.013.

94. Lefroy, K.S.; Murray, B.S.; Ries, M.E.; Curwen, T.D. A natural, cellulose-based microgel for water-in-oil emulsions. Food Hydrocoll. 2021, 113, 106408, https://doi.org/10.1016/j.foodhyd.2020.106408.

95. Zabar, S.; Lesmes, U.; Katz, I.; Shimoni, E.; Bianco-Peled, H. Structural characterization of amylose-long chain fatty acid complexes produced via the acidification method. Food Hydrocoll. 2010, 24, 347-357, https://doi.org/10.1016/j.foodhyd.2009.10.015.

96. Chen, Y-B.; Zhu, X-F.; Liu, T-X.; Lin, W-F.; Tang, C-H.; Liu, R. Improving freeze-thaw stability of soy nanoparticle-stabilized emulsions through increasing particle size and surface hydrophobicity. Food Hydrocoll. 2019, 87, 404-412, https://doi.org/10.1016/j.foodhyd.2018.08.020.

97. Ai, M.; Tang, T.; Zhou, L.; Ling, Z.; Guo, S.; Jiang, A. Effects of different proteases on the emulsifying capacity, rheological and structure characteristics of preserved egg white hydrolysates. Food Hydrocoll. 2019, 87, 933-942, https://doi.org/10.1016/j.foodhyd.2018.09.023.

98. Skelhon, T.S.; Grossiord, N.; Morgan, A.R.; Bon, S.A.F. Quiescent water-in-oil Pickering emulsions as a route toward healthier fruit juice infused chocolate confectionary. J. Mater. Chem. 2012, 22, 19289-19295, https://doi.org/10.1039/c2jm34233b.

99. Patel, A.R.; Seijen-ten-Hoorn, J.; Velikov, K.P. Colloidal complexes from associated water-soluble cellulose derivative (methylcellulose) and green tea polyphenol (Epigallocatechin gallate). J. Colloid Interf. Sci. 2011, 364, 317-323, https://doi.org/10.1016/j.jcis.2011.08.054.

100.Sun, J.; Liu, W.Y.; Feng, M.Q.; Xu, X.L.; Zhou, G.H. Characterization of olive oil emulsions stabilized by flaxseed gum. J. Food Eng. 2019, 247, 74-79, https://doi.org/10.1016/j.jfoodeng.2018.11.023.

101.Crupi, V.; Ficarra, R.; Guardo, M.; Majolino, D.; Stancanelli, R.; Venuti, V. UV-vis and FTIR-ATR spectroscopic techniques to study the inclusion complexes of genistein with $\beta$-cyclodextrins. J. Pharmaceut. Biomed. 2007, 44, 110-117, https://doi.org/10.1016/j.jpba.2007.01.054. 
102. Yang, S.; Chen, L.; Liu, S.; Hou, W.; Zhu, J.; Zhao, P.; Zhang, Q. Facile and sustainable fabrication of highperformance cellulose sponge from cotton for oil-in-water emulsion separation. J. Hazard. Mater. 2021, 408, 124408, https://doi.org/10.1016/j.jhazmat.2020.124408.

103.Zhao, H.; Kang, W.; Yang, H.; Huang, Z.; Zhou, B.; Sarsenbekuly, B. Emulsification and stabilization mechanism of crude oil emulsion by surfactant synergistic amphiphilic polymer system. Colloids Surf A Physicochem. Eng. Asp. 2021, 609, 125726, https://doi.org/10.1016/j.colsurfa.2020.125726.

104.Perles, C.E.; Guersoni, V.C.B.; Bannwart, A.C. Rheological study of crude oil/water interface - The effect of temperature and brine on interfacial film. J. Petrol. Sci. Eng. 2018, 162, 835-843, https://doi.org/10.1016/j.petrol.2017.11.010.

105.Gomes, A.; Costa, A.L.R.; Cunha, R.L. Impact of oil type and WPI/Tween 80 ratio at the oil-water interface: Adsorption, interfacial rheology and emulsion features. Colloid. Surface. B 2018, 164, 272-280, https://doi.org/10.1016/j.colsurfb.2018.01.032.

106. Artiga-Artigas, M.; Montoliu-Boneu, J.; Salvia-Trujillo, L.; Martín-Belloso, O. Factors affecting the formation of highly concentrated emulsions and nanoemulsions. Colloids Surf A Physicochem. Eng. Asp. 2019, 578, 123577, https://doi.org/10.1016/j.colsurfa.2019.123577.

107. Anton, N.; Saulnier, P.; Béduneau, A.; Benoit, J-P. Salting-Out Effect Induced by Temperature Cycling on a Water/Nonionic Surfactant/Oil System. J. Phys. Chem. B 2007, 111, 3651-3657, https://doi.org/10.1021/jp0664768.

108.Erni, P.; Fischer, P.; Windhab, E.J.; Kusnezov, V.; Stettin, H.; Läuger, J. Stress and strain-controlled measurements of interfacial shear viscosity and viscoelasticity at liquid/liquid and gas/liquid interfaces. Rev. Sci. Instrum. 2003, 74, 4916-4924, https://doi.org/10.1063/1.1614433.

109.Tang, C.H.; Liu, F. Cold, gel-like soy protein emulsions by micro-fluidization: Emulsion characteristics, rheological and microstructural properties, and gelling mechanism. Food Hydrocoll. 2013, 30, 61-72, https://doi.org/10.1016/j.foodhyd.2012.05.008.

110.Liu, F.; Tang, C.H. Emulsifying properties of soy protein nanoparticles: Influence of the protein concentration and/or emulsification process. J. Agric. Food Chem. 2014, 62, 2644-2654, https://doi.org/10.1021/jf405348k.

111.Qiu, C.; Zhao, M.; McClements, D.J. Improving the stability of wheat protein stabilized emulsions: Effect of pectin and xanthan gum addition. Food Hydrocoll. 2015, 43, 377-387, https://doi.org/10.1016/j.foodhyd.2014.06.013.

112.Zhang, J-B.; Wu, N-N.; Yang, X-Q.; He, X-T.; Wang, L-J. Improvement of emulsifying properties of Maillard reaction products from $\beta$-conglycinin and dextran using controlled enzymatic hydrolysis. Food Hydrocoll. 2012, 28, 301-312, https://doi.org/10.1016/j.foodhyd.2012.01.006.

113. McDonald, R.E.; Hultin, H.O. Some characteristics of the enzymatic lipid peroxidation system in the microsomal fraction of flounder skeletal-muscle. J. Food Sci. 1987, 52, 15-21, https://doi.org/10.1111/j.1365-2621.1987.tb13964.x.

114.De la Peña-Gil, A.; Toro-Vázquez, J.F.; Rogers, M.A. Simplifying Hansen Solubility Parameters for Complex Edible Fats and Oils. Food Biophys. 2016, 11, 283-291, https://doi.org/10.1007/s11483-016-9440-9.

115.Silva, H.D.; Beldíková, E.; Poejo, J.; Abrunhosa, L.; Serra, A.T.; Duarte, C.M.M.; Brányik, T.; Cerqueira, M.A.; Pinheiro, A.C.; Vicente, A.A. Evaluating the effect of chitosan layer on bioaccessibility and cellular uptake of curcumin nanoemulsions. J. Food Eng. 2019, 243, 89-100, https://doi.org/10.1016/j.jfoodeng.2018.09.007.

116.Salvia-Trujillo, L.; Verkempinck, S.H.E.; Zhang, X.; Van Loey, A.M.; Grauwet, T.; Hendrickx, M.E. Comparative study on lipid digestion and carotenoid bioaccessibility of emulsions, nanoemulsions and vegetable-based in situ emulsions. Food Hydrocoll. 2019, 87, 119-128, https://doi.org/10.1016/j.foodhyd.2018.05.053.

117. Acevedo, N.C.; Marangoni, A.G. Characterization of the nanoscale in triacylglycerol crystal networks. Cryst. Growth Des. 2010, 10, 3327-3333, https://doi.org/10.1021/cg100468e.

118. Marangoni, A.G.; Narine, S.S. Rheology of fats. In Structure and properties of fat crystal networks, $2 \mathrm{nd}$ ed. Marangoni A.G.; Wesdorp, L.H. (Eds.). Boca, Raton, FL: CRC Press. 2013, 125-145.

119. Karthink, P.; Anandharamakrishnan, C. Enhancing omega-3 fatty acids nanoemulsion stability and in-vitro digestibility through emulsifiers. J. Food Eng. 2016, 187, 92-105, https://doi.org/10.1016/j.jfoodeng.2016.05.003.

120. Valoppi, F.; Calligaris, S.; Barba, L.; Segatin, N.; Ulrih, N.P.; Nicoli, M.C. Influence of oil type on formation, structure, thermal, and physical properties of monoglyceride-based organogel. Eur. J. Lipid. Sci. Technol. 2016, 118, 1-10, https://doi.org/10.1002/ejlt.201500549. 
121.Cerqueira, M.A.; Fasolin, L.H.; Picone, C.S.F.; Pastrana, L.M.; Cunha, R.L.; Vicente, A.A. Structural and mechanical properties of organogels: Role of oil and gelator molecular structure. Food Res. Int. 2017, 96, 161-170, https://doi.org/10.1016/j.foodres.2017.03.021.

122.Rayner, M.; Marku, D.; Eriksson, M.; Sjöö, M.; Dejmek, P.; Wahlgren, M. Biomass-based particles for the formulation of Pickering type emulsions in food and topical applications. Colloid. Surface A 2014, 458, 4862, https://doi.org/10.1016/j.colsurfa.2014.03.053.

123. Cerqueira e Silva, K.F.; da Silva Carvalho, A.G.; Santos Rabelo, R.; Dupas Hubinger, M. Sacha inchi oil encapsulation: Emulsion and alginate beads characterization. Food Bioprod. Process 2019, 116, 118-129, https://doi.org/10.1016/j.fbp.2019.05.001.

124.Walker, R.; Decker, E.A.; McClements, D.J. Development of food-grade nanoemulsions and emulsions for delivery of omega-3 fatty acids: Opportunities and obstacles in the food industry. Food Funct. 2015, 6, 4255, https://doi.org/10.1039/c4fo00723a.

125.Borreani, J.; Leonardi, C.; Moraga, G.; Quiles, A.; Hernando, I. How do different types of emulsifiers/stabilizers affect the in vitro intestinal digestion of $\mathrm{O} / \mathrm{W}$ emulsions? Food Biophys. 2019, 14, 313325, https://doi.org/10.1007/s11483-019-09582-2.

126.Patel, A.R.; Dewettinck, K. Edible oil structuring: an overview and recent updates. Food Funct. 2016, 7, 2029, https://doi.org/10.1039/c5fo01006c.

127.Co, E.D.; Marangoni, A.G. Oleogels: An Introduction. In Edible Oleogels, 2nd ed. Marangoni, A.G.; Garti, N. Urbana, IL: AOCS Press. 2018, 1-29, https://doi.org/10.1016/B978-0-12-814270-7.00001-0.

128. Singh, H.; Ye, A.; Horne, D. Structuring food emulsions in the gastrointestinal tract to modify lipid digestion. Prog. Lipid Res. 2009, 48, 92-100, https://doi.org/10.1016/j.plipres.2008.12.001.

129.Zhuang, X.; Gaudino, N.; Clark, S.; Acevedo, N.C. Novel lecithin-based oleogels and oleogel emulsions delay lipid oxidation and extend probiotic bacteria survival. LWT Food Sci. Technol. 2021, 136, 110353, https://doi.org/10.1016/j.lwt.2020.110353.

130.Tian, Y.; Acevedo, N.C. Kinetic study on photostability of retinyl palmitate entrapped in policosanol oleogels. Food Chem. 2018, 255, 252-259, https://doi.org/10.1016/j.foodchem.2018.02.025.

131.Okuro, P.K.; Malfatti-Gasperini, A.A.; Vicente, A.A.; Cunha, R.L. Lecithin and phytosterols-based mixtures as hybrid structuring agents in different organic phases. Food Res. Int. 2018, 111, 168-177, https://doi.org/10.1016/j.foodres.2018.05.022.

132.Aguilar-Zárate, M.; Macias-Rodríguez, B.; Toro-Vázquez, J.F.; Marangoni, A.G. Engineering rheological properties of edible oleogels with ethylcellulose and lecithin. Carbohydr. Polym. 2019, 205, 98-105, https://doi.org/10.1016/j.carbpol.2018.10.032.

133.Iqbal, S.; Xu, Z.; Huang, H.; Chen, X.D. Controlling the rheological properties of oil phases using controlled protein polysaccharide aggregation and heteroaggregation in water-in-oil emulsions. Food Hydrocoll. 2019, 96, 278-287, https://doi.org/10.1016/j.foodhyd.2019.05.028.

134.Wang, P.; Cui, N.; Luo, J.; Zhang, H.; Guo, H.; Wen, P.; Ren, F. Stable water-in-oil emulsions formulated with polyglycerol polyricinoleate and glucono- $\delta$-lactone-induced casein gels. Food Hydrocoll. 2016, 57, 217 220, https://doi.org/10.1016/j.foodhyd.2016.01.013.

135.Massel, V.; Alexander, M.; Corredig, M. The Colloidal Behavior of Pectin Containing Water in Oil Emulsions as a Function of Emulsifier Concentration. Food Biophys. 2015, 10, 57-65, https://doi.org/10.1007/s11483-014-9355-2.

136.Zhang, K.; Mao, Z.; Huang, Y.; Xu, Y.; Huang, C.; Guo, Y.; Ren, X.; Liu, C. Ultrasonic assisted water-in-oil emulsions encapsulating macro-molecular polysaccharide chitosan: Influence of molecular properties, emulsion viscosity and their stability. Ultrason. Sonochem. 2020, 64, 105018, https://doi.org/10.1016/j.ultsonch.2020.105018.

137.Iqbal, S.; Hameed, G.; Baloch, M.K.; McClements, D.J. Structuring lipids by aggregation of acidic protein microspheres in W/O emulsions. LWT - Food Sci. Technol. 2013, 51, 16-22, http://dx.doi.org/10.1016/j.1wt.2012.10.014.

138.Luo, S-Z.; Hu, X-F.; Jia, Y-J.; Pan, L-H.; Zheng, Z.; Zhao, Y-Y.; Mu, D-D.; Zhong, X-Y.; Jiang, S-T. Camellia oil-based oleogels structuring with tea polyphenol-palmitate particles and citrus pectin by emulsiontemplated method: Preparation, characterization and potential application. Food Hydrocoll. 2019, 95, 76-87, https://doi.org/10.1016/j.foodhyd.2019.04.016.

139.Killian, L.A.; Coupland, J.N. Manufacture and Application of Water-in-Oil Emulsions to Induce the Aggregation of Sucrose Crystals in Oil: A Model for Melt-resistant Chocolate. Food Biophys. 2012, 7, 124131, https://doi.org/10.1007/s11483-012-9249-0. 
140.Bastida-Rodríguez, J. The Food Additive Polyglycerol Polyricinoleate (E-476): Structure, Applications, and Production Methods. Int. Sch. Res. Notices 2013, 2013, http://dx.doi.org/10.1155/2013/124767.

141.Israelachvili, J.N. Intermolecular and Surface Forces, 3rd ed. Academic Press, Santa Barbara, California, USA, 2015, https://doi.org/10.1016/C2011-0-05119-0.

142.Serrien, G.; Geeraerts, G.; Ghosh, L.; Joos, P. Dynamic surface properties of adsorbed protein solutions: BSA, casein and buttermilk. Colloids Surf. 1992, 68, 219-233, https://doi.org/10.1016/0166-6622(92)80208J.

143. Tyusenkov, A.S.; Rubtsov, A.V. The effect of electrization on the properties of flowing water oil emulsion. Mat. Sci. Eng. 2019, 734, 012165, https://doi.org/10.1088/1757-899X/734/1/012165.

144.Nadin, M.; Rousseau, D.; Ghosh, S. Fat crystal-stabilized water-in-oil emulsions as controlled release systems. LWT - Food Sci. Technol. 2014, 56, 248-255, https://doi.org/10.1016/j.lwt.2013.10.044.

145.Wijarnprecha, K.; Aryusuk, K.; Santiwattana, P.; Sonwai, S.; Rousseau, D. Structure and rheology of oleogels made from rice bran wax and rice bran oil. Food Res. Int. 2018, 112, 199-208, https://doi.org/10.1016/j.foodres.2018.06.005.

146. Yang, J.; Qiu, C.; Li, G.; Jun Lee, W.; Ping Tan, C.; Lai, O.M.; Wang, Y. Effect of Diacylglycerol Interfacial Crystallization on the Physical Stability of Water-in-Oil Emulsions. Food Chem. 2020, 327, 127014, https://doi.org/10.1016/j.foodchem.2020.127014.

147.Liu, L.; Kerr, W.L.; Kong, F. Characterization of lipid emulsions during in vitro digestion in the presence of three types of nanocellulose. J. Colloid Interface Sci. 2019, 545, 317-329, https://doi.org/10.1016/j.jcis.2019.03.023.

148.Qian, C.; Decker, E.A.; Xiao, H.; McClements, D.J. Physical and chemical stability of $\beta$-carotene-enriched nanoemulsions: Influence of $\mathrm{pH}$, ionic strength, temperature, and emulsifier type. Food Chem. 2012, 132, 1221-1229, https://doi.org/10.1016/j.foodchem.2011.11.091.

149. Salminen, H.; Weiss, J. Electrostatic adsorption and stability of whey protein-pectin complexes on emulsion interfaces. Food Hydrocoll. 2014, 35, 410-419, https://doi.org/10.1016/j.foodhyd.2013.06.020.

150.Cai, X.; Du, X.; Zhu, G.; Cao, C. Induction effect of $\mathrm{NaCl}$ on the formation and stability of emulsions stabilized by carboxymethyl starch/xanthan gum combinations. Food Hydrocoll. 2020, 105, 105776, https://doi.org/10.1016/j.foodhyd.2020.105776.

151.Taha, A.; Ahmed, E.; Hu, T.; Xu, X.; Pan, S.; Hu, H. Effects of different ionic strengths on the physicochemical properties of plant and animal proteins-stabilized emulsions fabricated using ultrasound emulsification. Ultrason. Sonochem. 2019, 58, 104627, https://doi.org/10.1016/j.ultsonch.2019.104627.

152.Zhang, Y.; An, Z.; Cui, G.; Li, J. Stabilized complex film formed by co-adsorption of $\beta$-lactoglobulin and phospholipids at liquid/liquid interface. Colloids Surf. A-Physicochem. Eng. Asp. 2003, 223, 11-16, https://doi.org/10.1016/s0927-7757(03)00099-2.

153. Gülseren, Í.; Corredig, M. Interactions at the interface between hydrophobic and hydrophilic emulsifiers: Polyglycerol polyricinoleate (PGPR) and milk proteins, studied by drop shape tensiometry. Food Hydrocoll. 2012, 29, 193-198, https://doi.org/10.1016/j.foodhyd.2012.03.010.

154.Dickinson, E.; Matsumura, Y. Time-dependent polymerization of $\beta$-lactoglobulin through disulphide bonds at the oil-water interface in emulsions. Int. J. Biol. Macromol. 1991, 13, 26-30, https://doi.org/10.1016/01418130(91)90006-G.

155. Bhuyan, A.K. On the mechanism of SDS-induced protein denaturation. Biopolymers 2010, 93, 186-199, https://doi.org/10.1002/bip.21318.

156.Wang, Y.; Yan, W.; Li, R.; Jia, X.; Cheng, Y. Impact of deamidation on gliadin-based nanoparticle formation and curcumin encapsulation. J. Food Eng. 2019, 260, 30-39, https://doi.org/10.1016/j.jfoodeng.2019.04.020.

157.Wang, Y.; Yan, W.; Jia, X.; Cheng, Y. Improving stability of gliadin-based Pickering emulsions by deamidation. J. Food Eng. 2020, 271, 109773, https://doi.org/10.1016/j.jfoodeng.2019.109773.

158.Cornec, M.; Wilde, P.J.; Gunning, P.A.; Mackie, A.R.; Husband, F.A.; Parker, M.L.; Clark, D.C. Emulsion Stability as Affected by Competitive Adsorption Between an Oil-Soluble Emulsifier and Milk Proteins at the Interface. J. Food Sci. 1998, 63, 39-43, https://doi.org/10.1111/j.1365-2621.1998.tb15671.x.

159.Liu, Y.; Yan, C.; Chen, J.; Wang, Y.; Liang, R.; Zou, L.; McClements, D.J.; Liu, W. Enhancement of betacarotene stability by encapsulation in high internal phase emulsions stabilized by modified starch and tannic acid. Food Hydrocoll. 2020, 109, 106083, https://doi.org/10.1016/j.foodhyd.2020.106083.

160. Bordenave, N.; Hamaker, B.R.; Ferruzzi, M.G. Nature and consequences of non-covalent interactions between flavonoids and macronutrients in foods. Food Funct. 2014, 5, 18-34, https://doi.org/10.1039/c3fo60263j. 
161.Roy, S.; Kar, B.; Das, S.; Datta, R. Effect of hydrogen bonding and hydrophobicity on gel emulsions by benzenesulphonamide moiety-based amphiphiles: entrapment and release of vitamin B12. Chemical Papers 2020, 74, 2635-2652, https://doi.org/10.1007/s11696-020-01102-8.

162.Zhao, Z.; Lu, M.; Mao, Z.; Xiao, J.; Huang, Q.; Lin, X.; Cao, Y. Modulation of interfacial phenolic antioxidant distribution in Pickering emulsions via interactions between zein nanoparticles and gallic acid. Int. J. of Biol. Macromol. 2020, 152, 223-233, https://doi.org/10.1016/j.ijbiomac.2020.02.136.

163.Dai, T.; Li, T.; Li, R.; Zhou, H.; Liu, C.; Chen, J.; McClements, D.J. Utilization of plant-based proteinpolyphenol complexes to form and stabilize emulsions: Pea proteins and grape seed proanthocyanidins. Food Chem. 2020, 329, 127219, https://doi.org/10.1016/j.foodchem.2020.127219.

164.Lupi, F.R.; Greco, V.; Baldino, N.; de Cindio, B.; Fischer, P.; Gabriele, D. The effects of intermolecular interactions on the physical properties of organogels in edible oils. J. Colloid Interfac. 2016, 483, 154-164, https://doi.org/10.1016/j.jcis.2016.08.009.

165.Neumann, S.M.; Wittstock, N.; Van der Schaaf, U.S.; Karbstein, H.P. Interactions in water in oil in water double emulsions: Systematical investigations on the interfacial properties and emulsion structure of the outer oil in water emulsion. Colloid. Surface. A 2018, 537, 524-531, https://doi.org/10.1016/j.colsurfa.2017.10.070.

166.Lulli, M.; Benzi, R.; Sbragaglia, M. Metastability at the Yield-Stress Transition in Soft Glasses. Phys. Rev. X 2018, 8, 21031, https://doi.org/10.1103/PhysRevX.8.021031.

167.Jiang, J.; Song, Z.; Wang, Q.; Xu, X.; Liu, Y.; Xiong, Y.L. Ultrasound-mediated interfacial protein adsorption and fat crystallization in cholesterol-reduced lard emulsion. Ultraso. Sonochem. 2019, 58, 104641, https://doi.org/10.1016/j.ultsonch.2019.104641. 